\title{
A 2D Coupled Atmosphere-Ocean Model Study of Air-Sea Interactions during a Cold Air Outbreak over the Gulf Stream
}

\author{
HuiJie Xue And ZiQin Pan \\ School of Marine Sciences, University of Maine, Orono, Maine \\ JOHN M. BANE JR. \\ Department of Marine Sciences, University of North Carolina, Chapel Hill, North Carolina
}

(Manuscript received 30 July 1998, in final form 21 June 1999)

\begin{abstract}
The two-dimensional, Advanced Regional Prediction System (ARPS) has been coupled with the Princeton Ocean Model to study air-sea interaction processes during an extreme cold air outbreak over the Gulf Stream off the southeastern United States. Emphases have been placed on the development of the mesoscale front and local winds in the lower atmosphere due to differential fluxes over the land, the cold shelf water, and the warm Gulf Stream, and on how the mesoscale front and the local winds feed back to the ocean and modify the upperocean temperature and current fields. Model results show that a shallow mesoscale atmospheric front is generated over the Gulf Stream and progresses eastward with the prevailing airflow. Behind the front, the wind intensifies by as much as $75 \%$ and a northerly low-level wind maximum with speeds near $5 \mathrm{~m} \mathrm{~s}^{-1}$ appears. The low-level northerly winds remain relatively strong even after the front has progressed past the Gulf Stream. The total surface heat flux in the coupled experiment is about $10 \%$ less than the total surface heat flux in the experiment with fixed SST, suggesting that the oceanic feedback to the atmosphere might not be of leading importance. On the other hand, the response of the upper-ocean velocity field to the local winds is on the order of $20 \mathrm{~cm} \mathrm{~s}^{-1}$, dominating over the response to the synoptic winds. This suggests the modification in the atmosphere by airsea fluxes, which induces the locally enhanced winds, has considerable impact on the ocean. That is, there is significant atmospheric feedback to the ocean through the heat-flux-enhanced surface winds.
\end{abstract}

\section{Introduction and background}

One of the most striking weather features over the east coast of North America is the frequent occurrence of wintertime, synopic-scale cyclones. During the cold air outbreak phase of such a cyclone, cold and dry polar air can sweep eastward off the continent and over the northwestern Atlantic Ocean. This typically induces excessive heat and moisture fluxes from the ocean to the atmosphere due to large air-sea temperature differences. One example is the cold air outbreak of 28-30 January 1986 , in which the maximum observed air-sea temperature difference reached $23 \mathrm{~K}$ (Grossman and Betts 1990) and the total heat flux exceeded $1500 \mathrm{~W} \mathrm{~m}^{-2}$ over the Gulf Stream (H. Xue et al. 1995). These large fluxes play an important role in mesoscale atmospheric processes, including coastal frontogenesis (Riordan 1990; Huang and Raman 1990), coastal cyclogenesis (Newton

Corresponding author address: Dr. H. Xue, School of Marine Sciences, Room 218, University of Maine, 5741 Libby Hall, Orono, ME 04469-5741.

E-mail: hxue@maine.edu and Holopainen 1990; Liou et al. 1990), the formation of coastal low-level jets (Doyle and Warner 1990, 1993), and the generation of Gulf Stream rainbands (Hobbs 1987; Huang and Raman 1992). Such large fluxes are also instrumental in altering the upper-ocean temperature and current fields during a cold air outbreak (Adamec and Elsberry 1985; Bane and Osgood 1989; Chao 1992; H. Xue et al. 1995; Xue and Bane 1997).

Heat, moisture, and momentum transfers between the atmosphere and the ocean are determined by the airsea temperature difference, wind speed, and stability of the atmospheric surface layer. As a cold air mass sweeps eastward during a cold air outbreak, temperature differences between the air and the underlying surface are usually small over the land, increase over the cold shelf water, and become rather large over the warm Gulf Stream water. The large land-shelf water-Gulf Stream temperature contrasts give rise to a nonhomogeneous flux distribution that can produce horizontal temperature gradients in the marine atmospheric boundary layer (MABL) and force a local atmospheric circulation. A strong atmospheric coastal front may develop as a result of the land-sea temperature contrast, differential surface roughness due to the varying ocean surface wave field, 
and irregular orography (Bosart 1975, 1981; Riordan 1990; Doyle and Warner 1990). The vertical stability of the lower atmosphere can be weakened by the development of a baroclinic zone in the coastal front. The available potential energy associated with the baroclinic zone appears to be the primary energy source for coastal cyclogenesis (Liou et al. 1990).

Mesoscale coastal processes along the eastern seaboard of the United States have been examined in several numerical studies. Warner et al. (1990) simulated the MABL circulation forced by the Gulf Stream sea surface temperature (SST) gradients. Their results showed that the strong SST gradient across the Gulf Stream front can produce distinct signatures in the MABL thermal, pressure, wind, and moisture fields. While sensible heating is the necessary condition for triggering a Gulf Stream forced circulation, latent heating eventually becomes dominant in driving the circulation in the MABL. Since neither ambient airflow nor cold air source were incorporated into their model, the results of Warner et al. (1990) can be viewed as isolated mesoscale circulations produced by the differential thermal forcing across the Gulf Stream under climatologically averaged winter conditions. By including the ambient airflow, Huang and Raman (1990) found that for onshore airflow the convergence zone and updraft are nearly stationary in the vicinity of the western edge of the Gulf Stream due to the blocking effect of the Appalachian Mountains, whereas for an offshore flow associated with a winter cyclone, the circulation front and the Gulf Stream rainband propagate downwind (farther offshore) as they evolve.

Oceanic responses to cold air outbreaks include modification of the upper-ocean thermal structure and current field. During the Genesis of Atlantic Lows Experiment (GALE), Bane and Osgood (1989) observed that the cold air outbreak of 28-30 January 1986 deepened the ocean mixed layer (OML) over the outer shelf and across the Gulf Stream on average by $35 \mathrm{~m}$, and it decreased the OML temperature by about $1^{\circ} \mathrm{C}$. In the absence of a cold air outbreak, the heat content variation over the shelf is mainly caused by the intrusion of warm Gulf Stream meanders (Atkinson et al. 1989; Lee et al. 1989), while in the Gulf Stream a heat balance is maintained by a mild heat loss to the atmosphere, the heat exchange between the shelf water and the Gulf Stream due to meanders and frontal eddies, and the downstream heat transport in the Gulf Stream jet. However, during cold air outbreaks excessive heat transfer to the atmosphere is mainly balanced by the cooling of the upper water column (H. Xue et al. 1995; Xue and Bane 1997). Adamec and Elsberry (1985) and H. Xue et al. (1995) showed that cooling and winds can both modify the upper-ocean current structure. Cooling causes convective mixing that enhances momentum exchange in the vertical. The result is a decrease of the Gulf Stream speed at the surface and an increase of speed in the lower mixed layer. Wind effects include the decrease or increase of the Gulf Stream speed by the wind-driven, along-stream Ekman transport and the shift of the Gulf Stream's path by the cross-stream Ekman transport.

The forced ocean models of Adamec and Elsberry (1985) and H. Xue et al. (1995), for example, could only be expected to respond realistically if continuously observed momentum and heat fluxes are applied at the surface. Meteorological observations over the ocean are rare, and using measurements at a single station is insufficient for modeling these processes, since the mesoscale thermal structure and winds induced by differential heating vary strongly and cannot be resolved by a single station. Furthermore, the sea-to-air heat flux can induce mesoscale circulations in the lower atmosphere, which in turn can alter the upper-ocean circulation. Coupled atmosphere-ocean models are thus more suitable for this type of study.

Chao (1992) coupled a two-dimensional, dry atmospheric model with a two-dimensional ocean model and found that during a cold air outbreak, updraft and cyclonic wind shear are generated near the nose of the atmospheric cold front, rather than being phase locked with the major heating region over the Gulf Stream. The postfrontal downdraft is primarily responsible for the wind stress intensification over the coastal ocean. He also suggests that the conventional meteorological practice of fixing SST is a reasonable approximation on timescales less than one week. However, the ocean circulation is sensitive to air-sea interaction on similar timescales. Direct cooling of the Gulf Stream by cold air generally weakens the transport by a small amount, whereas the heat-flux-induced postfrontal downdraft generates a lowlevel westerly jet in the atmosphere, which weakens the Gulf Stream transport considerably. However, the use of a dry atmosphere model in Chao's (1992) study excludes the mechanism of latent heating, which has been seen to be the dominant forcing of mesoscale features in the MABL in this situation (Warner et al. 1990).

A two-way coupling between the atmosphere and the ocean, driven by the exchanges of heat and momentum, occurs during a cold air outbreak off the southeastern United States. As cold, dry air flows off the continent and over the shelf water and Gulf Stream, the air-sea temperature difference (temperature deficit) and the moisture difference between sea surface and atmospheric surface layer (moisture deficit) induce sensible heat transfer and evaporation from sea surface to the atmosphere. This results in increasing air temperature, decreasing SST, the reduction of upper-ocean heat content, and enhanced turbulent motions in both the MABL and the OML. If the temperature and moisture content of the air leaving the coast remain the same, then over the lifetime of this hypothetical cold air outbreak, fluxes of sensible heat and moisture from the ocean surface to atmosphere would decrease as the temperature and moisture deficits decrease. On the other hand, the temperature gradient across the Gulf Stream SST front would give rise to a low-level atmospheric front and 
local atmospheric circulation associated with the front. Along with the prevailing eastward synoptic airflow, strong winds would induce momentum transfer and modify the velocity field in the upper ocean. Furthermore, diurnal effects would modify this general pattern as daytime heating and subsequent boundary layer mixing over land tend to warm and dry the atmospheric mixed layer there, while nighttime cooling and moistening would act in the opposite direction. As this daytime (nighttime) air is advected from land to ocean, the air-sea temperature and moisture deficits will decrease (increase) the fluxes along the trajectory of the flow.

This paper seeks to explore quantitatively these processes and feedbacks via a coupled atmosphere-ocean model and in doing so elucidate the meteorological and oceanographic consequences of an intense cold air outbreak. We designate the eastward-moving cold air as the synoptic forcing, which is imposed on the atmospheric model as the upwind boundary condition. The mesoscale forcing is introduced by the differential heating across the Gulf Stream SST front, and we designate the SST-driven local atmospheric circulation as mesoscale features/winds. In this paper, the effect of reduced SST on the atmosphere is referred to as the feedback from the ocean to the atmosphere (i.e., there is modification of the upper-ocean temperature by the cold air, and the modified SST field then acts back upon the atmosphere). Similarly, the effect of the mesoscale winds on the ocean is referred to as the feedback from the atmosphere to the ocean (i.e., there is modification of the lower atmosphere due to the SST gradient, and the modified atmosphere then acts back upon the ocean).

The atmospheric and oceanic components of the coupled model are described briefly in section 2 . The principal distinction between this study and that of Chao (1992) is the inclusion of moisture physics and strong convection, as described by the nonhydrostatic equations in the atmospheric model. Furthermore, more sophisticated turbulence closure schemes are used in both the atmospheric and oceanic models for this study. Section 3 discusses results from the "fully coupled" experiment. Modifications to the MABL and the upper ocean are described and compared with observations and previous model results. Section 4 compares the results of the fully coupled experiment with the results of the "partially coupled" experiment in which the surface stress due to the mesoscale winds induced by differential heating is turned off, and with the results of the "uncoupled" experiment in which the atmospheric model is forced by the fixed SST. Feedback processes between the MABL and the upper ocean are discussed. A summary is given in section 5. In addition, a sensitivity study of the atmospheric model to various parameterizations is included in the appendix.

\section{The two-dimensional coupled atmosphere-ocean model}

The coupled model consists of three components: an atmospheric model, an oceanic model, and a coupling scheme. As a cold front sweeps across eastern North America and moves over the adjacent sea surface, it is often oriented almost parallel to the coastline of the southeastern United States; thus, the atmospheric conditions are highly coherent over a large distance following the Gulf Stream in the South Atlantic Bight. For this reason the two-dimensional approach is adopted. Here, two-dimensional means that there are no alongcoast gradients in the horizontal pressure gradient force, velocity, temperature, or moisture; however, vertical advection, vertical flux divergence, and Coriolis forcing are allowed to force the along-coast momentum equation in both the atmospheric and the oceanic components of the model.

The atmospheric model is the Advanced Regional Prediction System (ARPS) developed by the Center for Analysis and Prediction of Storms at the University of Oklahoma. It can be reduced easily to a two-dimensional version by assuming minimal grid points of 4 in the along-coast direction. Details about the model can be found in M. Xue et al. (1995). Briefly, the model is designed to predict small-scale and mesoscale weather events, and is nonhydrostatic because strong convection usually proceeds rapidly in developing storms. It includes momentum, heat (potential temperature), mass (pressure), six categories of water (water vapor, cloud water, rainwater, cloud ice, snow, and hail), and turbulence kinetic energy (TKE) equations plus the equation of state. At the air-land interface, ARPS incorporates the soil-vegetation model developed by Noilhan and Planton (1989) and Pleim and Xiu (1995) to calculate land surface temperature and soil surface moisture. In particular, the soil-vegetation model includes the diurnal cycle in its surface energy budget. ARPS allows options for parameterizing the subgrid-scale turbulence, moisture microphysics, and surface fluxes. An extensive sensitivity study has been completed to determine the appropriate parameterizations for typical cold air outbreak situations. As a result, a 1.5-order TKE closure scheme with isotropic subgrid-scale turbulence, and the surface flux model of Businger et al. (1971) with modifications for highly stable and highly unstable environments (Deardroff 1972), are chosen. A more detailed discussion on the sensitivity study is given in the appendix.

The oceanic model is a two-dimensional version of the Princeton Ocean Model (POM). The same model has been used by $H$. Xue et al. (1995) to study the oceanic response to cold air outbreaks using forced experiments. In the vertical the model adopts a sigma coordinate that is scaled to the water column. An implicit scheme is used that eliminates time constraints for the vertical coordinate and permits the use of fine resolution in the surface and bottom boundary layers. It contains an embedded, second-order turbulence closure scheme (Mellor and Yamada 1982) to provide mixing coefficients. The model also has a free surface and complete 


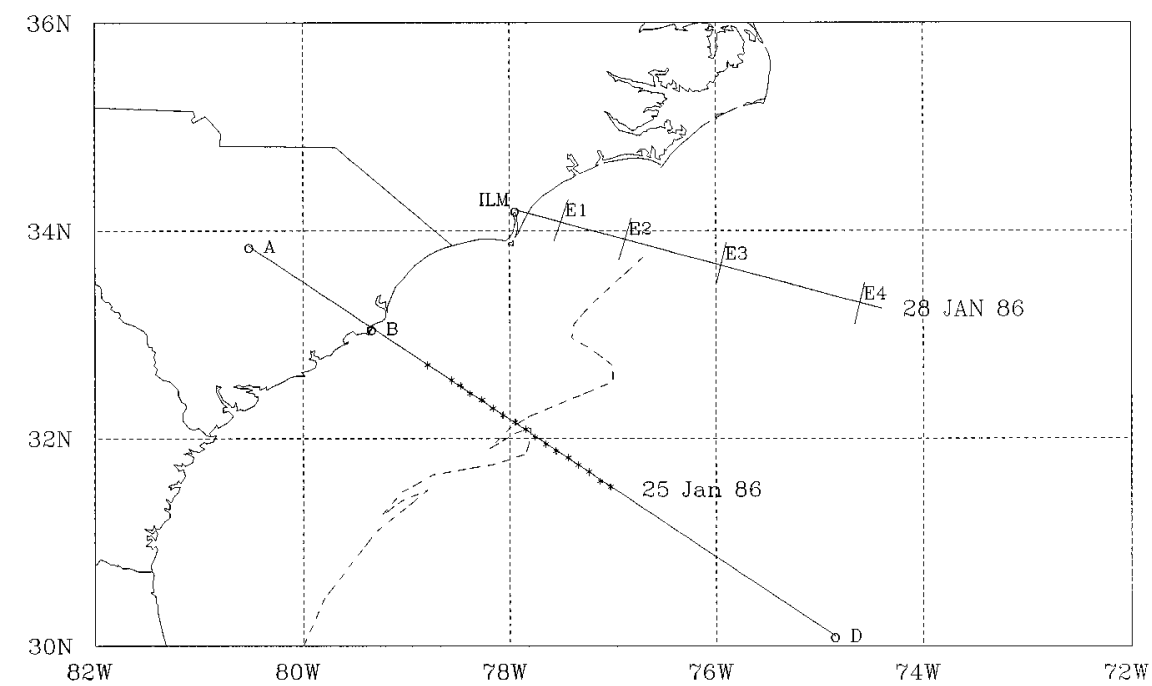

FIG. 1. Location map of the two-dimensional cross-sectional model domain. Here, A is the upwind boundary of the model, B is where the ocean grids start, and D is the seaward boundary of the model. The section overlays the 25 Jan 1986 NOAA P3 flight track. The asterisks are the locations of AXBTs dropped during the same flight. The dashed curve outlines the Gulf Stream front on 22 Jan 1986, which is almost perpendicular to the model cross section. Also shown to the north is the NCAR Electra flight track for 28 Jan 1986 and the positions of stacks of level legs (E1, E2, E3, and E4) where turbulence measurements were made. ILM represents the coastal weather station at Wilmington, NC.

thermodynamics. Details about the POM can be found in Blumberg and Mellor (1987) and Mellor (1998).

To couple the atmospheric model with the oceanic model, a concurrent process communication technique is used to establish the linkage between the two models such that the information (SST and surface fluxes) can be transferred from the atmospheric model to the oceanic model and vice versa. Since the atmospheric and the oceanic models use the same horizontal resolution in this study, no spatial interpolation along the surface is needed. Transfer of information is done by using two PIPEs (PIPE is a computer concept similar to a file). First, the atmospheric model is run to create two PIPEs (PIPE 1 and PIPE 2), it then FORKs a process to EXECUTE the ocean model such that the two models run synchronously. The atmospheric model calculates surface fluxes and stores them in PIPE 1, and the oceanic model calculates SST and stores it in PIPE 2. At the next concurrent time step, the atmospheric model takes the SST stored in PIPE 2, runs forward in time, and updates the surface fluxes in PIPE 1, while the oceanic model takes the surface fluxes stored in PIPE 1, runs forward in time, and updates the SST in PIPE 2. PIPE, FORK, and EXECUTE functions are all compiled using $\mathrm{C}$ and UNIX system calls.

\section{The fully coupled experiment}

\section{a. Experiment setup}

The two-dimensional, coupled, atmosphere-ocean model is first utilized to simulate air-sea interactions during the cold air outbreak of 28-30 January 1986.
The model domain is a cross section perpendicular to the Gulf Stream that extends from the North Carolina coast to the western Sargasso Sea (Fig. 1). The atmospheric domain is $640 \mathrm{~km}$ in the horizontal (from A to $\mathrm{D}$, with the first $140 \mathrm{~km}$ over the land) by $12 \mathrm{~km}$ in the vertical, while the oceanic domain is $500 \mathrm{~km}$ in the horizontal (from B to D) by $3 \mathrm{~km}$ in the vertical. The atmospheric model has 65 grid points in the horizontal with a uniform grid size of $10 \mathrm{~km}$ and 34 stretched levels in the vertical. The oceanic model has 51 grid points in the horizontal with the same grid size of 10 $\mathrm{km}$ and 51 levels in the vertical with finer resolution near the surface.

The atmospheric model is initialized using the Crosschain Loran Atmospheric Sounding System (CLASS) sounding at Wilmington, North Carolina, that was taken at 1200 UTC on 28 January 1986 (Fig. 2). Following Huang and Raman (1990), wind profiles used in the model have been smoothed (see Fig. 2a). The alongshore wind is set to zero, while the offshore wind is $10 \mathrm{~m} \mathrm{~s}^{-1}$ in the lower $2 \mathrm{~km}$ and gradually increases to $35 \mathrm{~m} \mathrm{~s}^{-1}$ at about $4.5 \mathrm{~km}$ above the surface. Thus, the primary baroclinicity exists in the offshore wind component between 2 and $4.5 \mathrm{~km}$. Associated with the baroclinic layer is a layer of strong stratification (Fig. 2b). Below this layer, the temperature is well mixed within the lowest kilometer. The lower atmosphere is very cold, about $-10^{\circ} \mathrm{C}$. Relative humidity is very low except near the surface.

The oceanic model is initialized with the same condition as that of H. Xue et al. (1995), in which the upperocean temperature observed on 25 January 1986 in the 

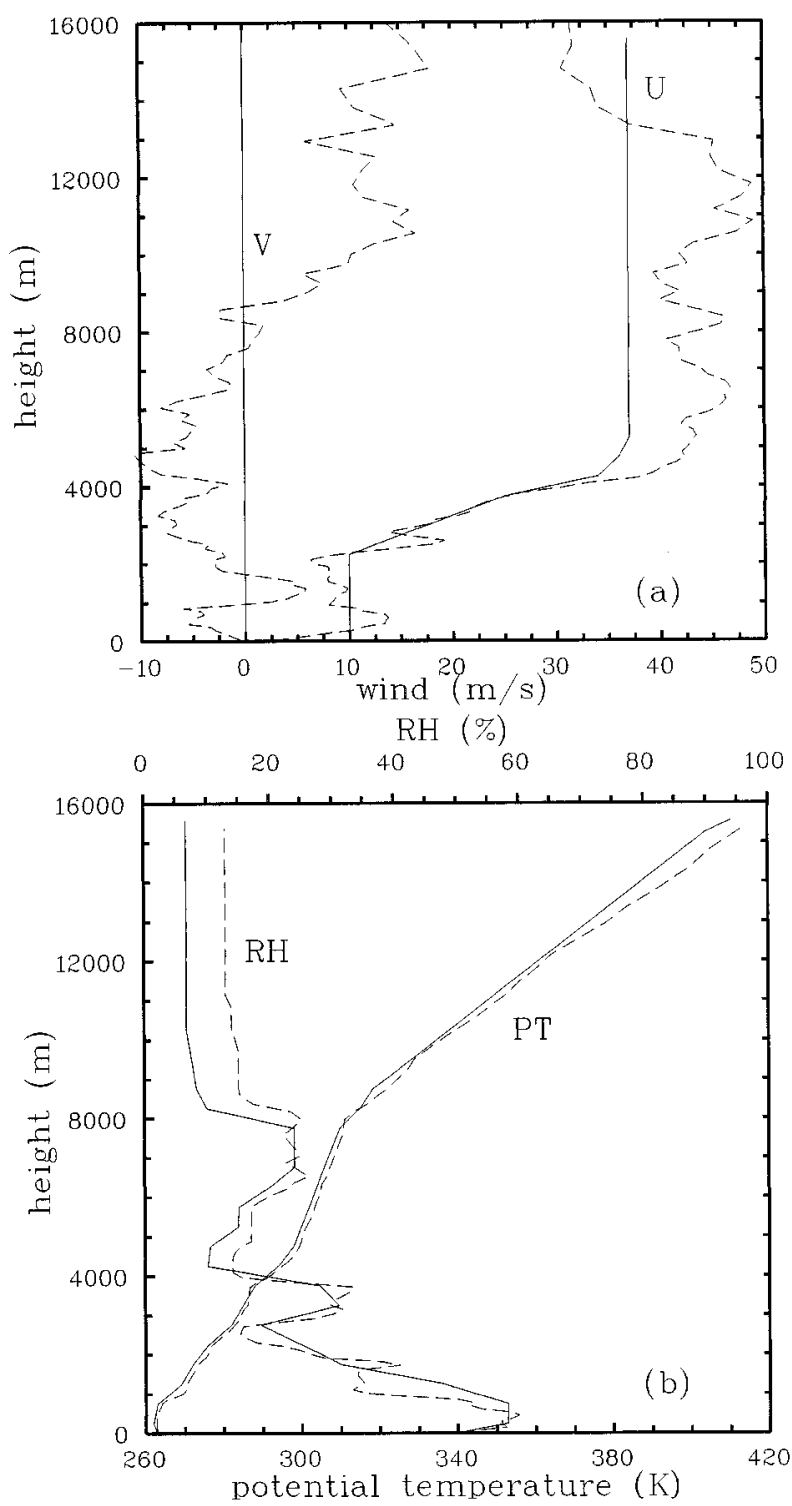

FIG. 2. Dashed curves are CLASS sounding profiles at Wilmington, NC, at 1200 UTC 28 Jan 1986: (a) offshore wind $(u)$ and alongshore wind $(v)$ in the model orientation, and (b) potential temperature and relative humidity. Solid curves are initial profiles used in the atmospheric model.

shelf water and the Gulf Stream from the surface to 350-m depth is patched to an analytical formulation of temperature below $350 \mathrm{~m}$. Downstream velocity is obtained by integrating the thermal wind relation and assuming zero velocity at the bottom. Following H. Xue et al. (1995) the oceanic model is first integrated without any atmospheric forcing for 50 days to reach a statistical equilibrium state. The equilibrium temperature and downstream velocity are shown in Fig. 3, and they are thought of as the oceanic condition prior to the cold air outbreak (i.e., the initial oceanic condition in the coupled model). The corresponding SST is also shown in Fig. 3. The temperature field includes a warm filament

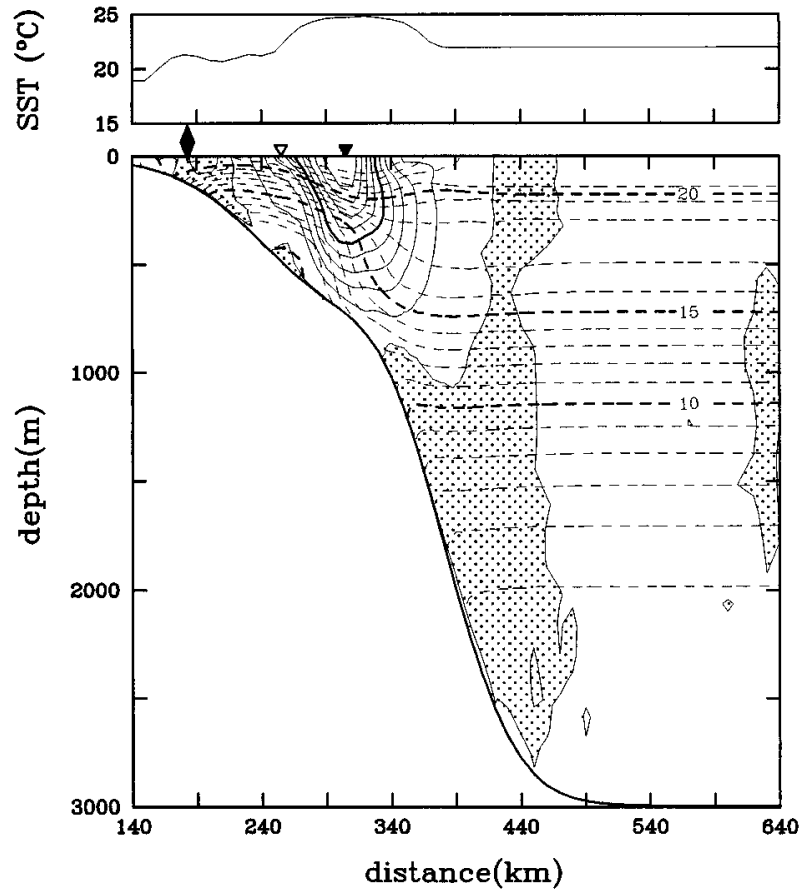

FIG. 3. Ocean temperature (dashed contours) and downstream velocity (solid contours) prior to the cold air outbreak. Contour intervals are $1{ }^{\circ} \mathrm{C}$ and $20 \mathrm{~cm} \mathrm{~s}^{-1}$. The shaded areas indicate southward flow. Also shown in the upper portion is the corresponding SST. The rhombus points to the location of the warm filament; the open triangle and the solid triangle indicate the SST front and the velocity core of the Gulf Stream prior to the cold air outbreak, respectively.

of Gulf Stream water over the shelf with surface temperature about $21.5^{\circ} \mathrm{C}$, a cold dome over the shelfbreak with surface temperature below $21^{\circ} \mathrm{C}$, and a core of warm Gulf Stream water $\left(>24^{\circ} \mathrm{C}\right)$ between 140 and 220 $\mathrm{km}$ from the coast. In Fig. 3, the rhombus points to the location of the warm filament; the open triangle and the solid triangle indicate the SST front and the velocity core of the Gulf Stream prior to the cold air outbreak, respectively. Both triangles remain at these fixed locations in subsequent figures as reference points. The model integration time begins at 0500 UTC [0000 eastern standard time (EST)] 28 January 1986.

A steady cold air advection (sounding profiles in Fig. 2), modified by the diurnal cycle over land, is prescribed at the upwind boundary of the atmospheric model (at site A in Fig. 1). The assumption of steady cold air advection is valid only for the period from immediately before to right after the cold air outbreak, which lasts about 1-2 days. The computation was carried out for 2 days so oceanic changes can be clearly detected. A radiation condition is applied at the downwind boundary at site D (see Fig. 1). The top boundary condition in the atmospheric model uses the radiation condition combined with Rayleigh damping, and the damping coefficient is $1 \mathrm{~s}^{-1}$. For the oceanic model, zero mass and zero heat flux are prescribed at the coast (site B in Fig. 1 ) and at the ocean floor, and a gravity wave radiation 
condition is applied at the offshore boundary. Since the offshore boundary is far from the Gulf Stream, computation is not sensitive to the boundary condition there.

\section{b. MABL structure}

Potential temperature $(\theta)$ and TKE in the lower half of the atmosphere at integration times of $6,12,18$, and $24 \mathrm{~h}$ are shown in Fig. 4. These panels illustrate the development of the MABL and a mesoscale thermal front in the MABL during the cold air outbreak. In general, the height of the MABL, inferred from the TKE distribution, increases offshore. At $6 \mathrm{~h}$, it is about 700 $\mathrm{m}$ at the coastline, $2300 \mathrm{~m}$ over the Gulf Stream core (the solid triangle), and $2500 \mathrm{~m}$ just east of the Gulf Stream core. The height reduces slightly to a constant altitude of $2300 \mathrm{~m}$ east of the Gulf Stream. Within the MABL $\theta$ increases from about $266 \mathrm{~K}$ at the coastline to about $272 \mathrm{~K}$ over the Gulf Stream core. This temperature change represents a lower-atmospheric thermal front to the west of the Gulf Stream core, resulting from the interplay of the cold air advection from upwind and the oceanic heating from below. Recall the synoptic wind near the surface is $10 \mathrm{~m} \mathrm{~s}^{-1}$ offshore, which translates to about $200 \mathrm{~km}$ advective distance in $6 \mathrm{~h}$. On the other hand, the initial condition prescribes a horizontally homogeneous layer of cold air over the ocean surface. Therefore, the thermal front seen in Fig. 4a is mainly due to the differential heating over the land, shelf water, and Gulf Stream.

At $12 \mathrm{~h}$ (1200 EST), the advective effect increases, especially in the western half of the domain. However, $\theta$ in the lower atmosphere near the coast increases as the land temperature increases due to the diurnal cycle. Oceanic heating still dominates the upwind cold advection in the eastern half of the domain; hence, $\theta$ in the MABL increases east of the Gulf Stream core. A potential temperature gradient is established throughout the MABL. The height of the MABL over the Gulf Stream core is about $2000 \mathrm{~m}$, but it exceeds $2500 \mathrm{~m}$ farther offshore. The largest increase in height occurs over the shoreward side of the stream. The structure of the MABL changes little from 12 to $18 \mathrm{~h}$, and the decrease in offshore potential temperature gradient is mainly due to the rising land temperature associated with the diurnal cycle. At $24 \mathrm{~h}$ the land temperature is again low, and upwind cold advection dominates the oceanic heating west of the Gulf Stream core, resulting in decreased $\theta$ and an increased potential temperature gradient. The shape of the MABL and the TKE values change very little. However, the location of the maximum TKE moves eastward.

The distribution and magnitude of the TKE in Fig. $4 \mathrm{~b}$ agree well with the model results of Huang and Raman (1991). Wayland and Raman (1989) reported a maximum value of $5 \mathrm{~m}^{2} \mathrm{~s}^{-2}$ for TKE observed in the surface layer near the Gulf Stream core during the 28 January 1986 cold air outbreak, and this value is rea- sonably reproduced in this experiment. Aircraft data collected on that date (note the aircraft survey line in Fig. 1) also show that $\theta$ increased offshore, about $12 \mathrm{~K}$ in $300 \mathrm{~km}$ with most of the increase (about $8 \mathrm{~K}$ ) occurring west of the Gulf Stream core (Grossman and Betts 1990). The potential temperature gradient predicted by this model is between 10 and $12 \mathrm{~K}$ over the first 300 $\mathrm{km}$, and the largest gradient appears west of the Gulf Stream core. It is worth pointing out that in this experiment $\theta$ is almost vertically constant in the lower MABL (vertical isentropes) and then increases with height (onshore-upward tilt of isentropes). Observations showed relatively constant potential temperature in the MABL over the shelf and most of the Gulf Stream but decreases in potential temperature with height east of the Gulf Stream (offshore-upward tilt of isentropes) (Grossman and Betts 1990). The offshore-upward tilt in the observed isentropes indicates that strong cold advection overpowers the heating from the ocean below and convective mixing in the MABL is relatively low (Huang and Raman 1991). One possible explanation for this difference between the observations and this simulation is that the numerical experiment is initialized with a horizontally homogeneous cold air mass, whereas in the real world the air far offshore is considerably warmer and more moist and, thus, is more in equilibrium with the underlying SST.

On the other hand, both Huang and Raman (1991) and Chao (1992) found slight decreases of potential temperature with height in the lower MABL (a noselike feature in the atmospheric temperature profile). Chao (1992) used a dry atmosphere model in which only sensible heat was considered so that convection in the MABL was much weaker. The difference in potential temperature distribution between the present study and Huang and Raman (1991), however, can be attributed largely to the different approaches in estimating the turbulence mixing length in two models. Huang and Raman (1991) included a second-order turbulence closure to calculate the TKE and the TKE dissipation rate, from which the turbulence mixing scale can be inferred. ARPS uses a 1.5-order turbulence closure in which the turbulence mixing length is related to grid size. For this study, subgrid-scale turbulence is assumed to be isotropic, and the model generates a level of TKE comparable to that of Huang and Raman (1991) but larger eddy viscosity values especially near the surface. If subgridscale turbulence is assumed to be anisotropic, the vertical mixing length scale equals the vertical grid increment, which is $100 \mathrm{~m}$ near the surface and one order less than that in the isotropic case. This results in a TKE level that is much too low, but shows a noselike feature in the atmospheric temperature profile (see the appendix).

\section{c. Mesoscale atmospheric circulation}

Figure 5 shows the development of mesoscale winds. At $6 \mathrm{~h}$ (Fig. 5b), there are two, opposite flowing, closed 
circulations in the lower atmosphere that result in an updraft region extending from $300 \mathrm{~km}$ offshore to about $460 \mathrm{~km}$ offshore and from the surface to about $2500 \mathrm{~m}$. Recall the front location at this hour (see Fig. 4a), and note that the updraft is ahead of the front. The downdraft behind the front is weaker than the updraft, and another much weaker downdraft exists farther offshore. The westerly surface wind behind the updraft increases by as much as $4 \mathrm{~m} \mathrm{~s}^{-1}$. Farther offshore it decreases by about $1 \mathrm{~m} \mathrm{~s}^{-1}$, resulting in a surface convergence zone under the updraft center. In contrast, 2 to $3 \mathrm{~km}$ above the surface the westerly wind behind the updraft decreases by 2-3 $\mathrm{m} \mathrm{s}^{-1}$, and the wind ahead of the updraft increases, resulting in a divergence zone above the updraft center. Vertical motions in the mid- and upper troposphere appear to be reversed in phase and weaker relative to those in the lower atmosphere. Associated with these cross-frontal circulations, an alongfront wind develops. A northerly wind greater than $1 \mathrm{~m} \mathrm{~s}^{-1}$ is found over the western side of the Gulf Stream, while a weaker southerly wind exists above and ahead of the northerly wind (Fig. 5a).

The mesoscale atmospheric circulation progresses eastward with the prevailing airflow and intensifies (Figs. 5c-h). By $12 \mathrm{~h}$, the maximum updraft has moved to about $600 \mathrm{~km}$ offshore, and the magnitude of the updraft has increased to $12 \mathrm{~cm} \mathrm{~s}^{-1}$. The westerly wind behind the updraft has reached $15.6 \mathrm{~m} \mathrm{~s}^{-1}$ at the surface but it has decreased to about $5 \mathrm{~m} \mathrm{~s}^{-1}$ at $3000-\mathrm{m}$ height. Stronger convergence (divergence) under (above) the updraft center is expected, although the seaward anticyclonic circulation in the lower atmosphere has moved out of the study area. The low-level northerly wind exceeds $4 \mathrm{~m} \mathrm{~s}^{-1}$, and the southerly wind above is almost $3 \mathrm{~m} \mathrm{~s}^{-1}$. The propagation speed of the three-dimensional mesoscale circulation inferred from the intermediate hours (not shown) is about $9.5 \mathrm{~m} \mathrm{~s}^{-1}$, slower than the surface wind speed. One exception to the eastward progression of the mesoscale circulation is the downdraft region behind the front; it appears to move offshore at a much slower pace. At 18 and $24 \mathrm{~h}$, the maximum updraft region is farther offshore, and the vertical velocity in the study area has decreased. Even so, the lowlevel westerly and northerly winds remain strong over the Gulf Stream.

\section{d. Cloud and precipitation}

Aircraft observations on 28 January 1986 during the cold air outbreak revealed that the sky was clear from eastern North Carolina to about $60 \mathrm{~km}$ offshore. A scattered stratocumulus deck appeared over the shelf water, and the sky was heavily overcast from about $120 \mathrm{~km}$ offshore (seaward from the western edge of the Gulf Stream). As the aircraft flew eastward, it was observed that the cloud base lowered from about $1000 \mathrm{~m}$ west of the Gulf Stream to about 500 m east of the Gulf Stream, while the cloud top was observed to rise from about
$1000 \mathrm{~m}$ to about $2400 \mathrm{~m}$ in the same direction. Cumulus congestus were present over the eastern edge of the Gulf Stream where snow showers were encountered (Grossman and Betts 1990).

Clouds, regardless of type, are described in ARPS using a single variable $\left(q_{c}\right.$, the mixing ratio of cloud water). Using $q_{c}$, the presence of clouds during a cold air outbreak is simulated reasonably well (Fig. 6). At 6 $\mathrm{h}$, the cloud base west of the Gulf Stream core is at about $800 \mathrm{~m}$, while east of the stream core it is at about $700 \mathrm{~m}$. Grossman and Betts (1990) suggested that the lowering of the cloud base offshore is due to the effect of moistening outweighing the warming of the subcloud layer. Since the model is initialized with a spatially uniformed cold and dry air mass, farther offshore both the temperature and the moisture deficit are much larger in the model than in the real world. The lack of significant lowering of the modeled cloud base suggests the effect of the excessive temperature deficit overpowering the effect of the excessive moisture deficit in the model. There is no precipitation at this hour (Fig. 6b).

Six hours later $(t=12 \mathrm{~h})$ the clouds begin to dissipate; however, the cloud base rises in the seaward direction, indicating there is excessive sensible heat transport in the model especially on the far eastern side of the domain. The cloud top rises from $1200 \mathrm{~m}$ over the midshelf, to about $2500 \mathrm{~m}$ over the eastern edge of the Gulf Stream, and then to about $3600 \mathrm{~m}$ near the maximum updraft. Precipitation occurs east of the Gulf Stream core with a maximum located near the center of the updraft. At 18 and 24 h, clouds west of the Gulf Stream dissipate gradually, and the sky over the shelf is mostly cloud free. However, the western edge of the cloudy region is almost stationary because of the slow eastward progression of the downdraft region seen in Figs. $5 \mathrm{f}$ and $5 \mathrm{~h}$. The eastern half of the domain remains under cloud cover at these times. Heavy precipitation, along with the strong updraft, has moved away from the study area, while mild precipitation continues seaward from the eastern side of the Gulf Stream.

\section{e. Fluxes at the air-sea interface}

Temporal-spatial distributions of the total surface heat flux (sensible plus latent) and wind stress during the simulated cold air outbreak are shown in Figs. 7a and $7 \mathrm{~b}$, respectively. Since the model is initialized with spatially uniformed cold air, initially the heat flux mimics the SST pattern. A weak maximum occurs over the warm Gulf Stream filament, followed by a slight decrease over the cold core and a strong maximum over the main body of the Gulf Stream. The heat flux lowers again east of the Gulf Stream. It decreases with time during the first few hours because the air-sea temperature contrast decreases as a result of the ocean to atmosphere heat transfer. Beginning at $3 \mathrm{~h}$, the spatial pattern is complicated by the arriving cold air from the northwest. The cold air tends to first increase the heat 

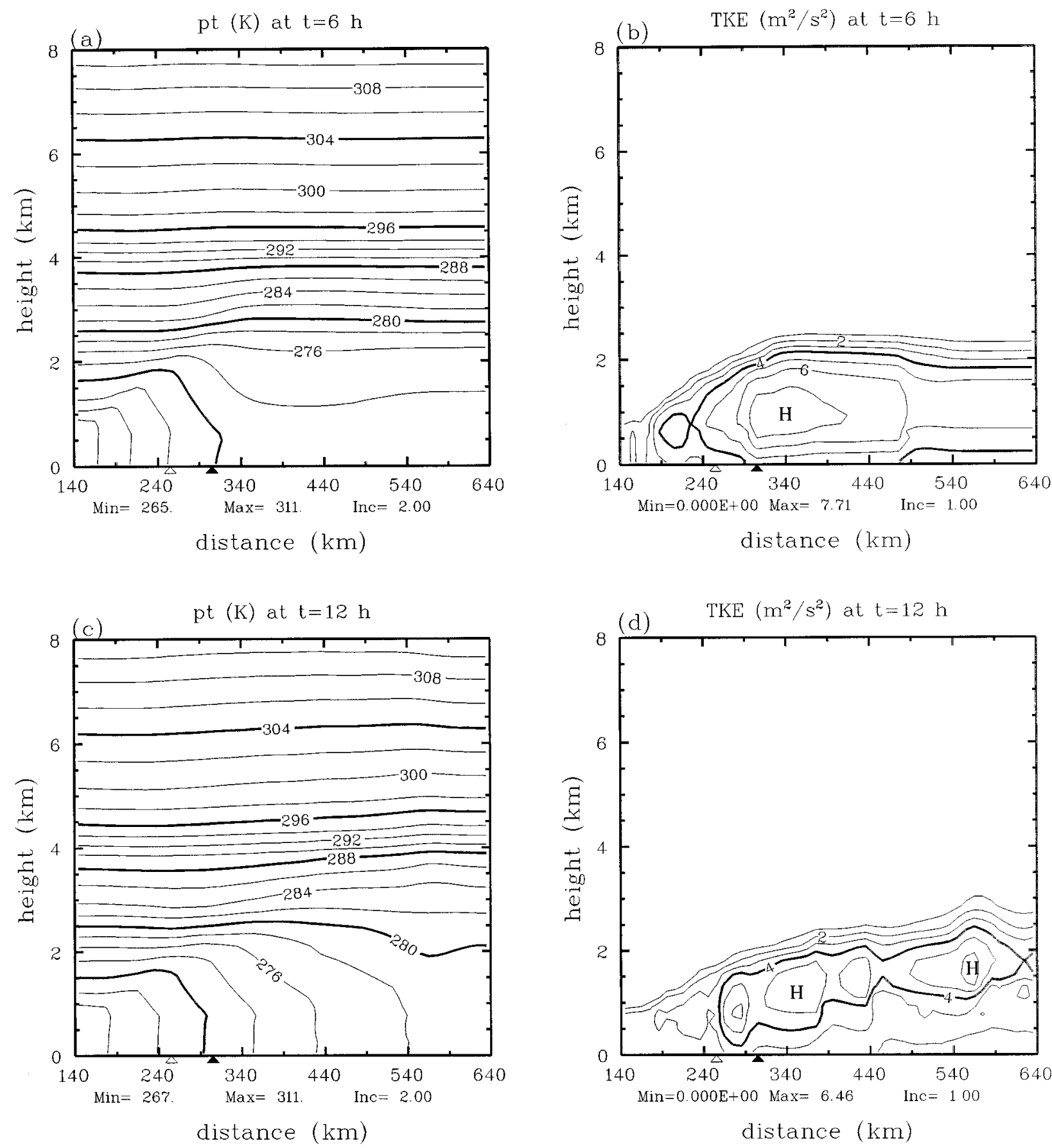

FIG. 4. Potential temperature and TKE in the fully coupled experiment. (a), (c), (e), and (g) Potential temperature at 6, 12, 18, and $24 \mathrm{~h}$, respectively. (b), (d), (f), and (h) TKE at $6,12,18$, and $24 \mathrm{~h}$, respectively. Contour intervals are $2 \mathrm{~K}$ for potential temperature and $1 \mathrm{~m}^{2}$ $\mathrm{s}^{-2}$ for TKE. In each panel the horizontal axis is the offshore distance in km starting at the land-ocean crossing point (site B in Fig. 1).

flux over the warm Gulf Stream filament and later over the main body of the Gulf Stream (around $5 \mathrm{~h}$ ), meanwhile farther offshore the air is still being warmed up and the heat flux continues to decrease. The cold air continues to progress eastward, resulting in the increase of the heat flux along the way, which gives rise to the wedge-shaped isolines east of the Gulf Stream. The slope of the wedge indicates the speed of the eastward advancing cold air. The front of the cold air moves out of the study area at about $14 \mathrm{~h}$, and afterward the heat flux remains relatively steady everywhere inside the study area except for a minor decrease starting near the coast shortly after $12 \mathrm{~h}$. Recall the diurnal cycle over the land (Fig. 4) and the fact that this diurnal fluctuation 

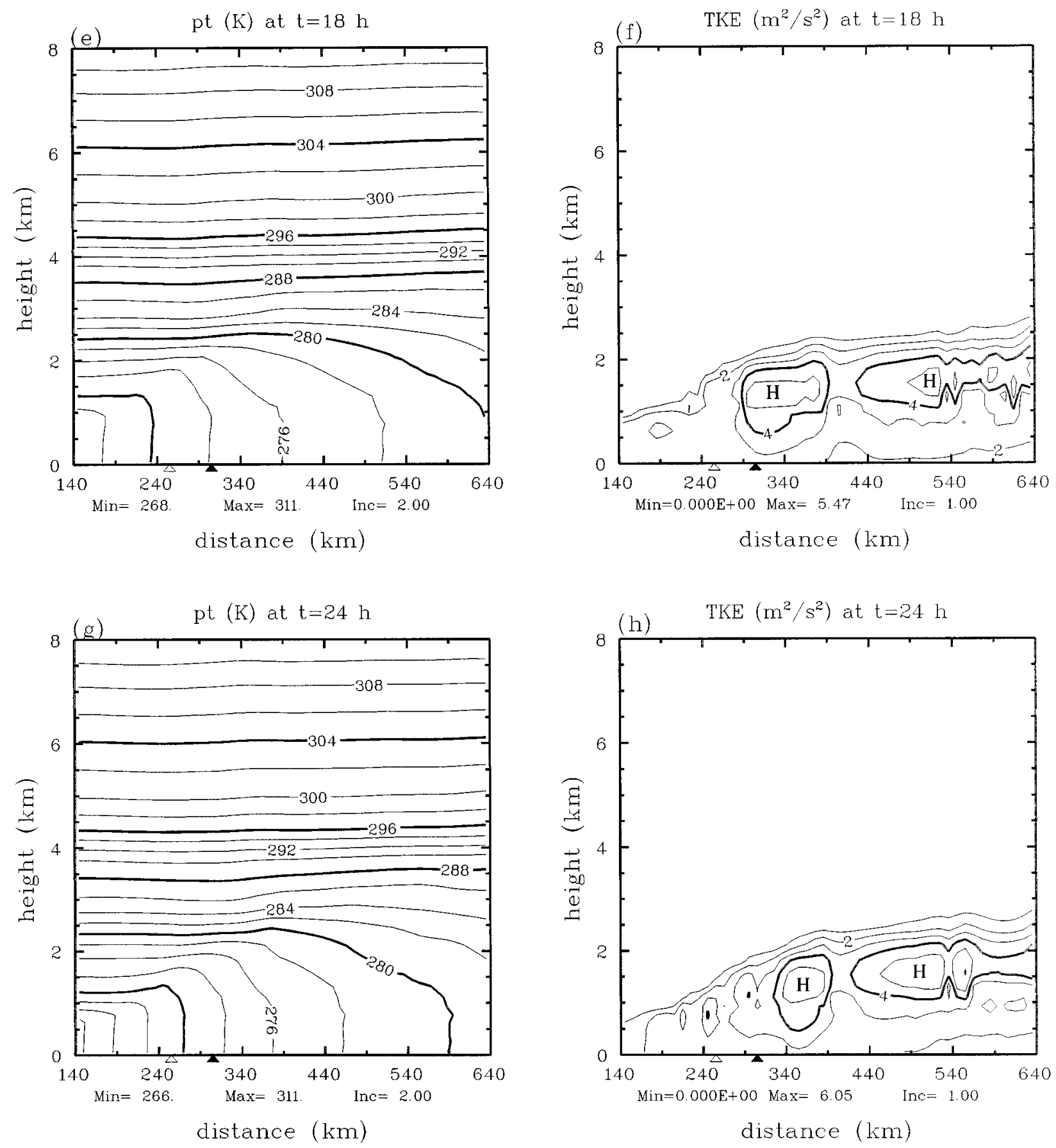

FIG. 4. (Continued)

in air temperature is being advected over the ocean. Afternoon warming appears as a minimum in the heat flux beginning near the coast around $14 \mathrm{~h}$. This minimum is advected eastward by the prevailing airflow and reaches the main body of the Gulf Stream around $17 \mathrm{~h}$. The minimum can still be traced east of the Gulf Stream. The magnitude of the heat flux varies from $800 \mathrm{~W} \mathrm{~m}^{-2}$ offshore before the arrival of the cold air to about 1300
$\mathrm{W} \mathrm{m}^{-2}$ over the Gulf Stream. The latter falls between the low estimate of $1100 \mathrm{~W} \mathrm{~m}^{-2}$ (Grossman and Betts 1990) and the high estimate of $1500 \mathrm{~W} \mathrm{~m}^{-2}$ (H. Xue et al. 1995).

The surface wind stress pattern shown in Fig. 7b demonstrates similar characteristics. One expects the surface wind to increase due to the ocean-to-atmosphere heat flux in that the heat flux induces vertical mixing, and 

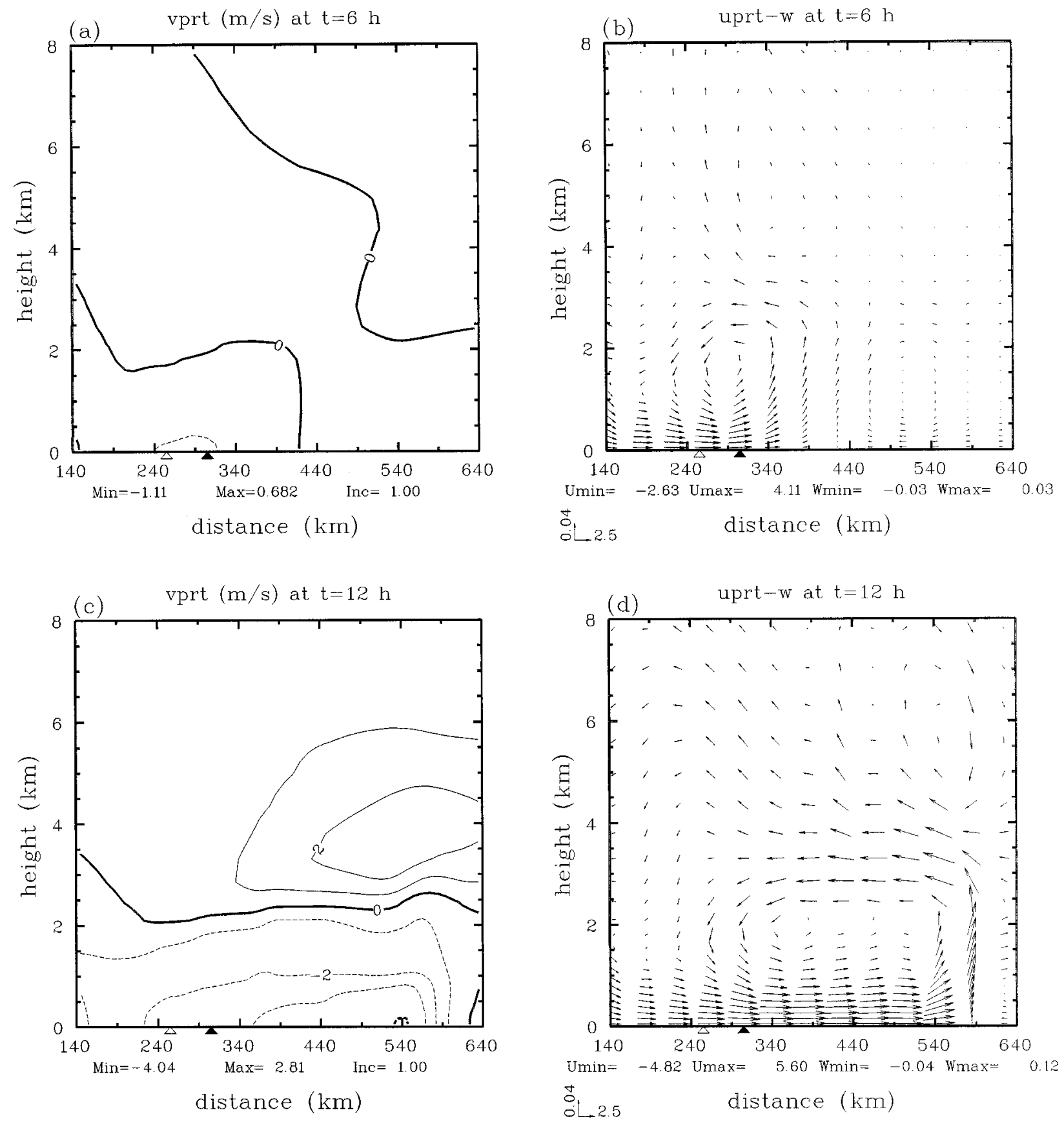

FIG. 5. Similar to Fig. 4 but for perturbation velocity field. (a), (c), (e), and (g) Alongshore wind anomalies at 6, 12, 18, and 24 h, respectively. Dashed contours represent northerly winds. Contour interval is $1 \mathrm{~m} \mathrm{~s}^{-1}$. (b), (d), (f), and (h) The $u-w$ anomaly vectors at 6 , 12, 18, and $24 \mathrm{~h}$, respectively. Vector scales are shown in $\mathrm{m} \mathrm{s}^{-1}$ at the lower-left corners of these panels.

the mixing in turn brings the higher momentum air to the surface. However, the mixing has to reach above $2-\mathrm{km}$ height for the surface winds to increase, because the synoptic airflow is constant from the surface to 2 $\mathrm{km}$. The surface wind stress begins to increase noticeably after the arrival of the upwind cold air around 3 $\mathrm{h}$, and a convergence zone appears ahead of the cold air and moves eastward in the direction of the prevailing wind. There are two regions of substantial wind stress increase (as indicated by relatively close isolines): one over the warm filament and another over the western side of the Gulf Stream. In general, wind stress increases with time as the ocean-to-atmosphere heat flux continuously fuels the mixing in the MABL. For a brief period in the afternoon, warmer temperatures are advected over the Gulf Stream as a result of land heating. These warm- 

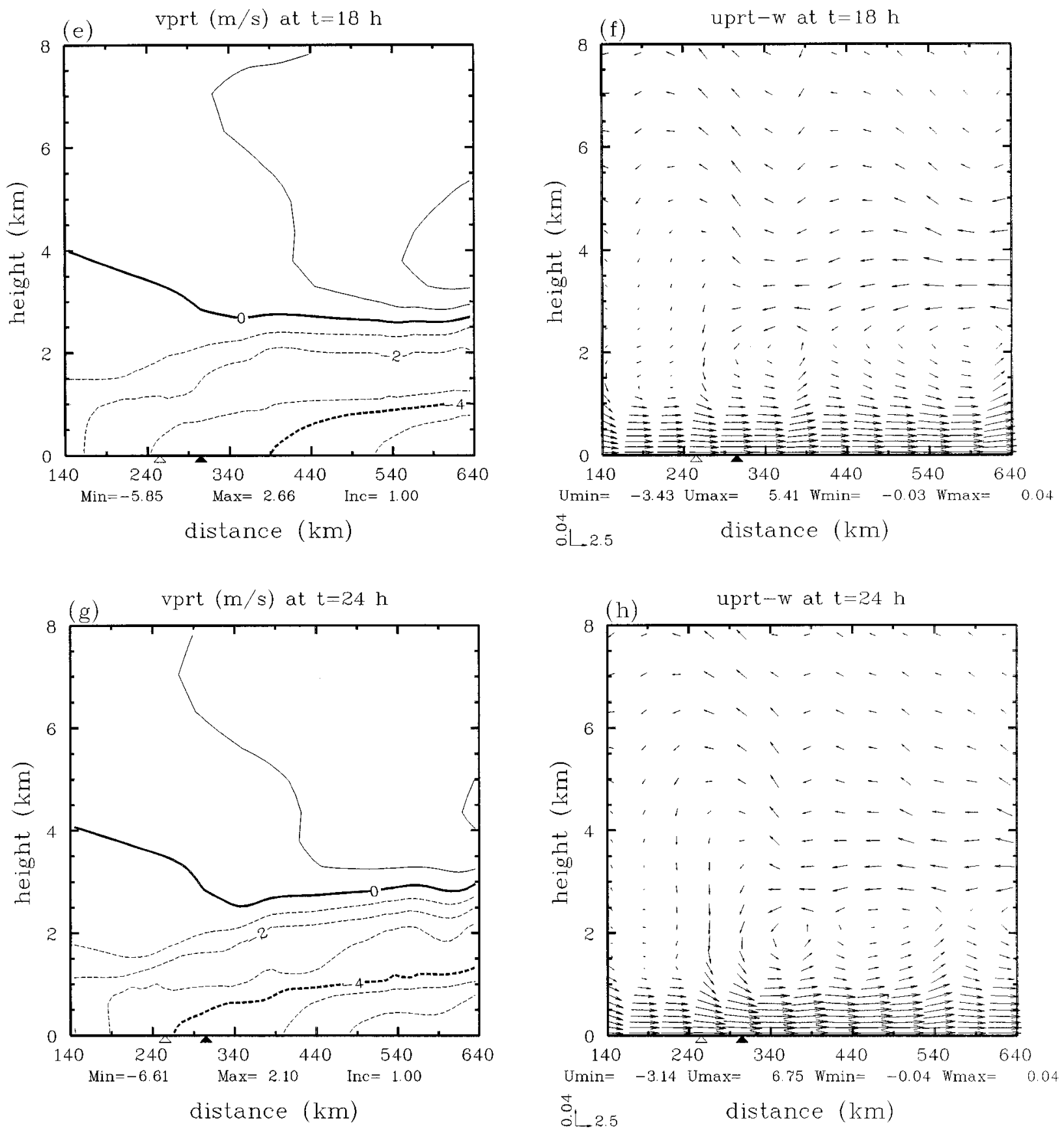

FIG. 5. (Continued)

er temperatures tend to reduce the surface instability over the stream, thus reducing mixing of higher momentum air to the surface and lowering surface wind speeds and wind stress. Due to the Coriolis effect, winds also tend to the northwest with time and distance. Although the magnitude of the mesoscale wind seen in Fig. 5 reaches about $75 \%$ of the synoptic wind $(10 \mathrm{~m}$ $\mathrm{s}^{-1}$ ), the total wind stress increases by as much as a factor of 4. Furthermore, strong mesoscale winds remain over the Gulf Stream even after the low-level front has moved away from the study area (Figs. 5e-h). It is thus expected that mesoscale winds play an essential role in modifying the upper ocean.

\section{f. Modification of the upper ocean}

Modification to the upper ocean in this coupled model is similar to that computed by H. Xue et al. (1995) using a forced ocean model. A time sequence of temperature distribution in the upper $250 \mathrm{~m}$ is shown in Fig. 8. The 


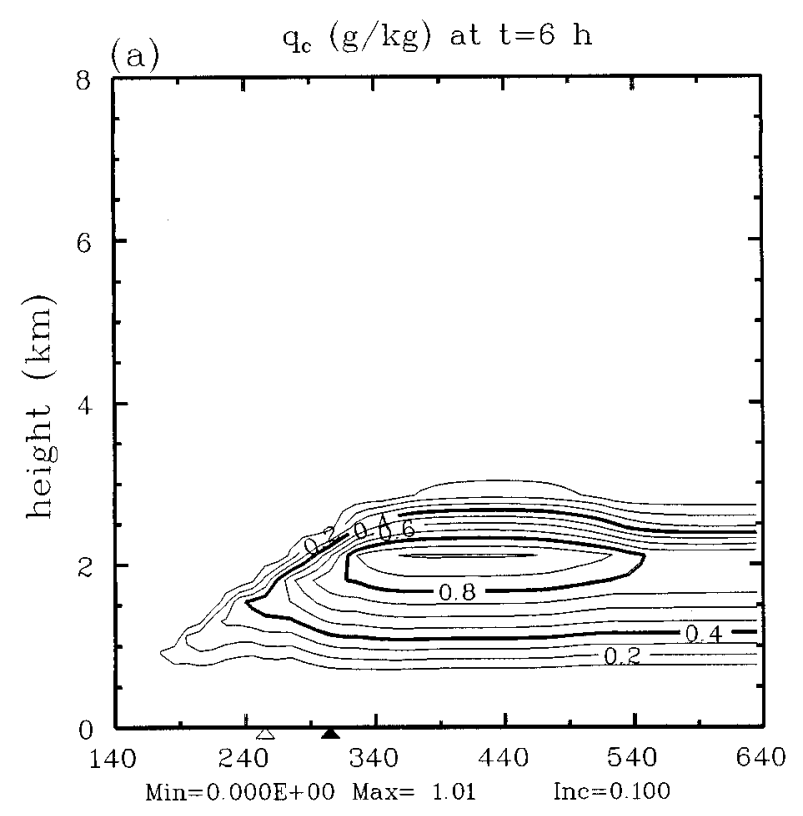

distance $(\mathrm{km})$

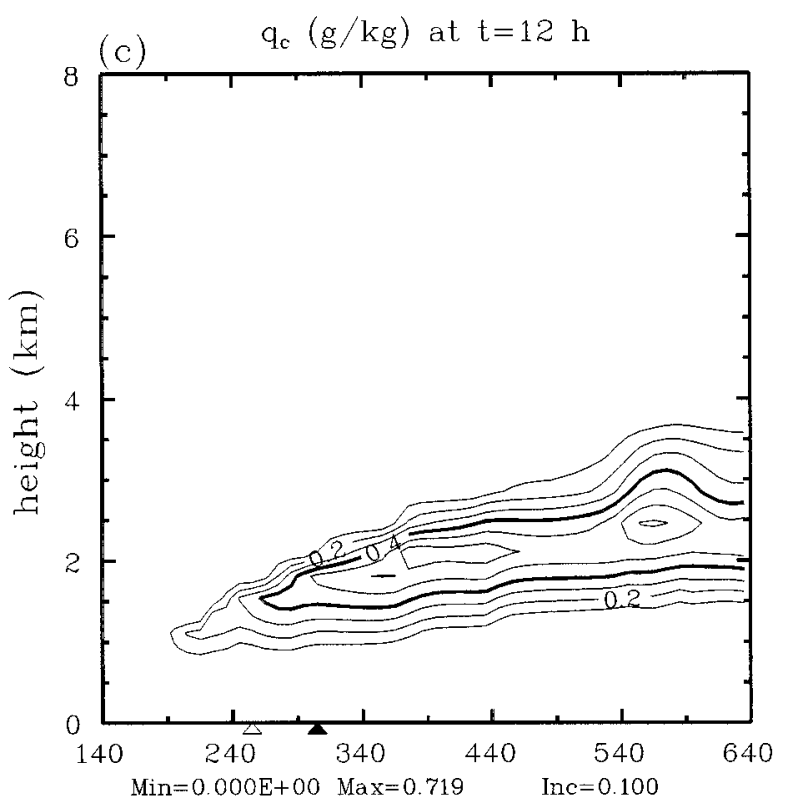

distance $(\mathrm{km})$

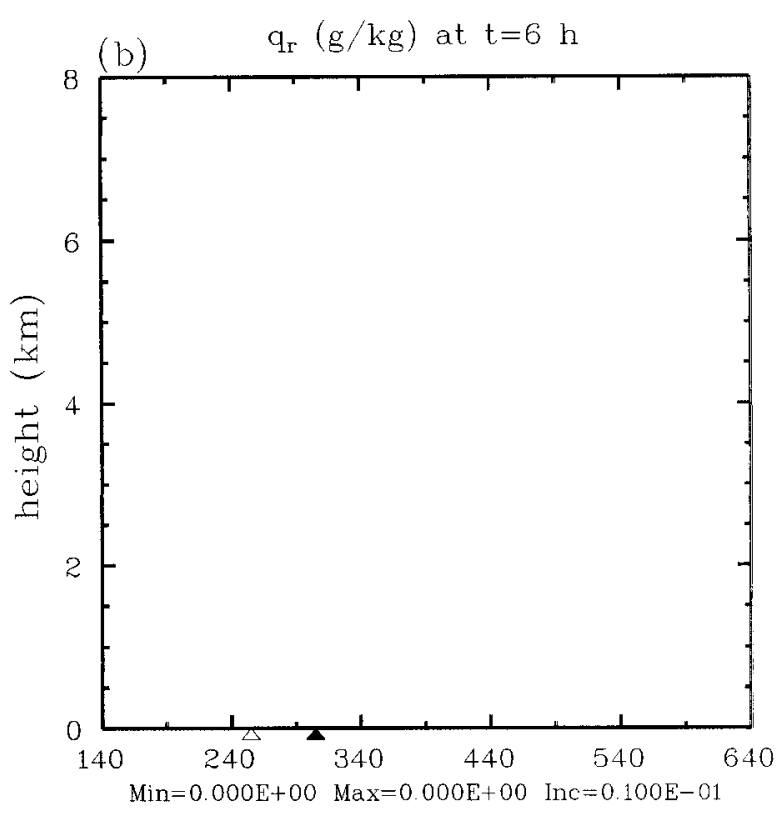

distance $(\mathrm{km})$

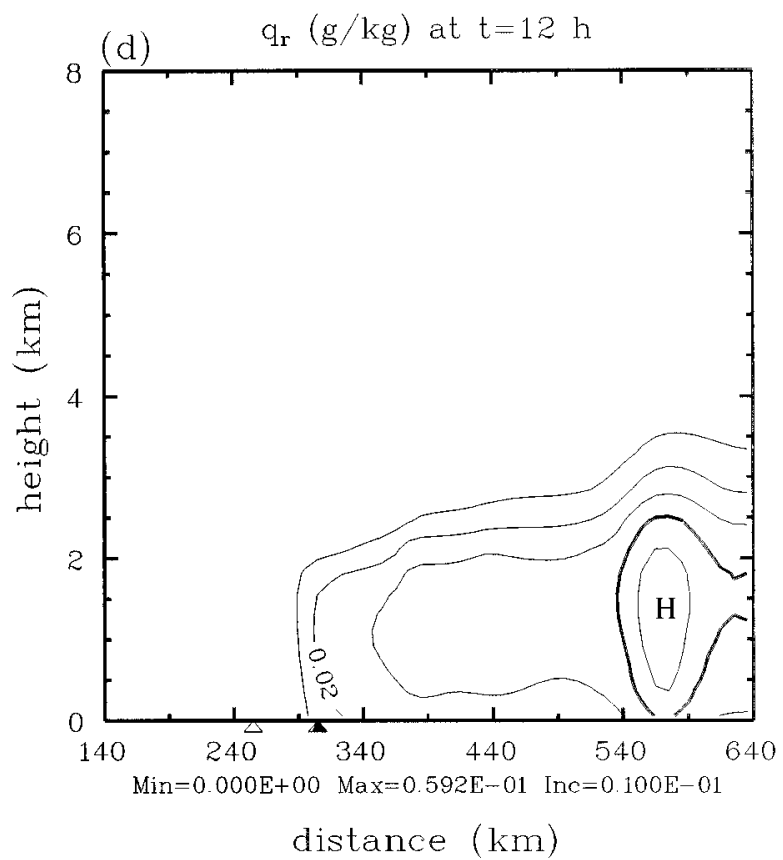

FIG. 6. Similar to Fig. 4 but for mixing ratios of cloud water and rainwater. (a), (c), (e), and (g) Mixing ratios of cloud water at 6, 12, 18 , and $24 \mathrm{~h}$, respectively. (b), (d), (f), and (h) Mixing ratios of rainwater at $6,12,18$, and $24 \mathrm{~h}$, respectively. Contour intervals are $0.1 \mathrm{~g}$ $\mathrm{kg}^{-1}$ for cloud water and $0.01 \mathrm{~g} \mathrm{~kg}^{-1}$ for rainwater.

shaded area in each panel represents the OML, taken to be the layer adjacent to the ocean's surface in which there is essentially no vertical temperature gradient. At $0 \mathrm{~h}$ (top panel), the nearshore water column is well mixed, while the OML over the shelf break is relatively shallower over the cold dome. The OML in the Gulf Stream generally deepens in the seaward direction.
However, there exist double mixed layers on the eastern side of the Gulf Stream with the lighter surface Gulf Stream water overlaying the heavier offshore water (Bane and Osgood 1989; H. Xue et al. 1995). Figure 8 depicts the upper mixed layer whose base appears to rise on the eastern side of the stream. The most noticeable changes are the deepening of the ocean mixed layer 

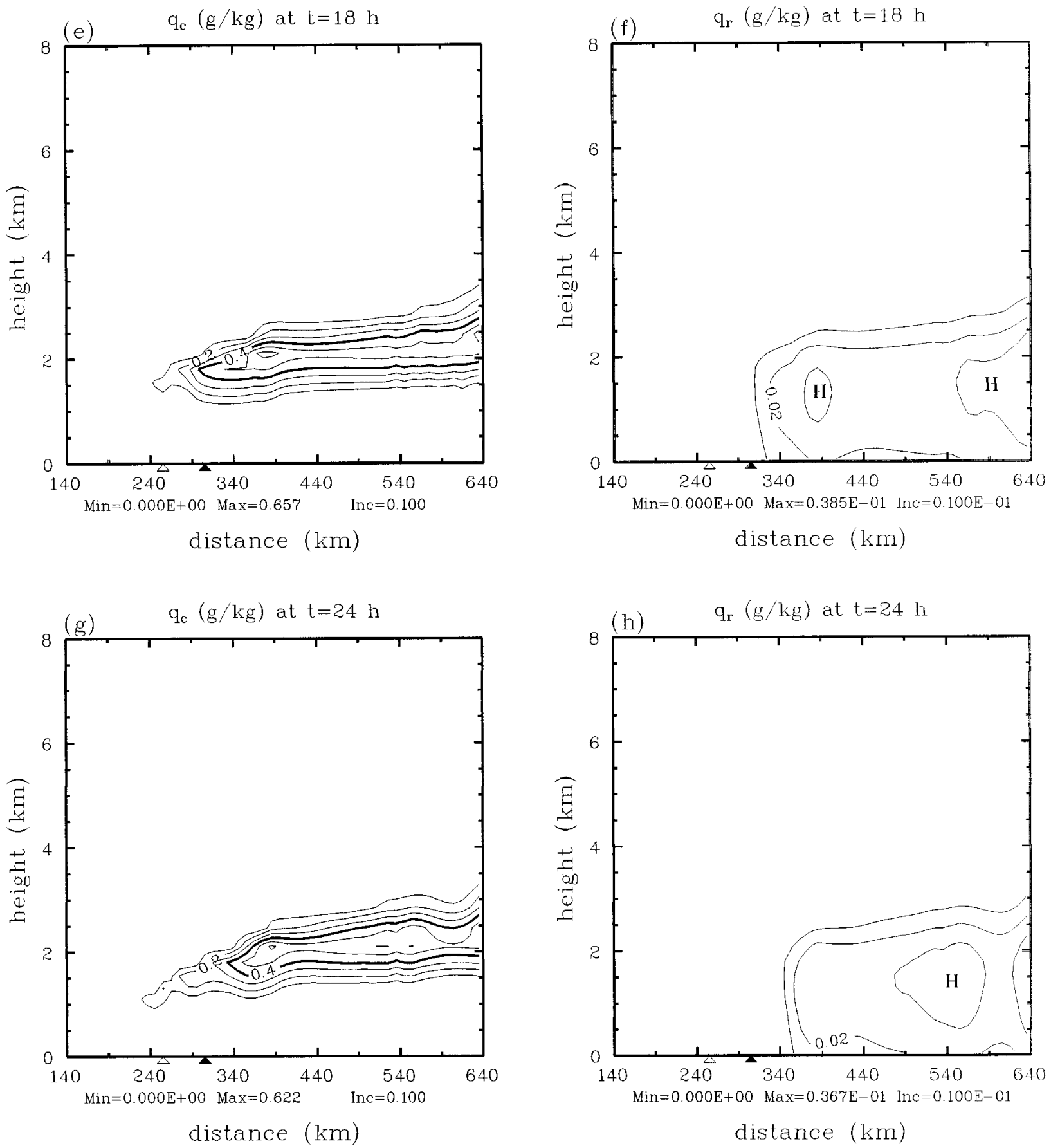

FIG. 6. (Continued)

and the decrease of surface temperature. H. Xue et al. (1995) have shown that these changes are caused by the heat loss from the upper ocean to the atmosphere, that convective mixing due to buoyancy fluxes is stronger than the wind-generated mixing, and that the wind affects the temperature distribution through Ekman velocity, which advects the stream in the on/offshore direction. As expected, there is no detectable change in temperature below the mixed layer.
Comparisons of SST and mixed layer depth (distance between the surface and the base of the mixed layer) at 0 and $48 \mathrm{~h}$ are shown in Figs. 9a and 9b, respectively. Differences are larger in the shelf and in the Gulf Stream, where SST decreases by $1^{\circ} \mathrm{C}$ and mixed layer depth increases by $40 \mathrm{~m}$. The reason is that the shelf and the Gulf Stream each lose more heat to the atmosphere than farther offshore, because by the time the air reaches the eastern side of the Gulf Stream, the air-sea 


\section{(a) Total Heat Flux $\left(W / \mathrm{m}^{2}\right)$}
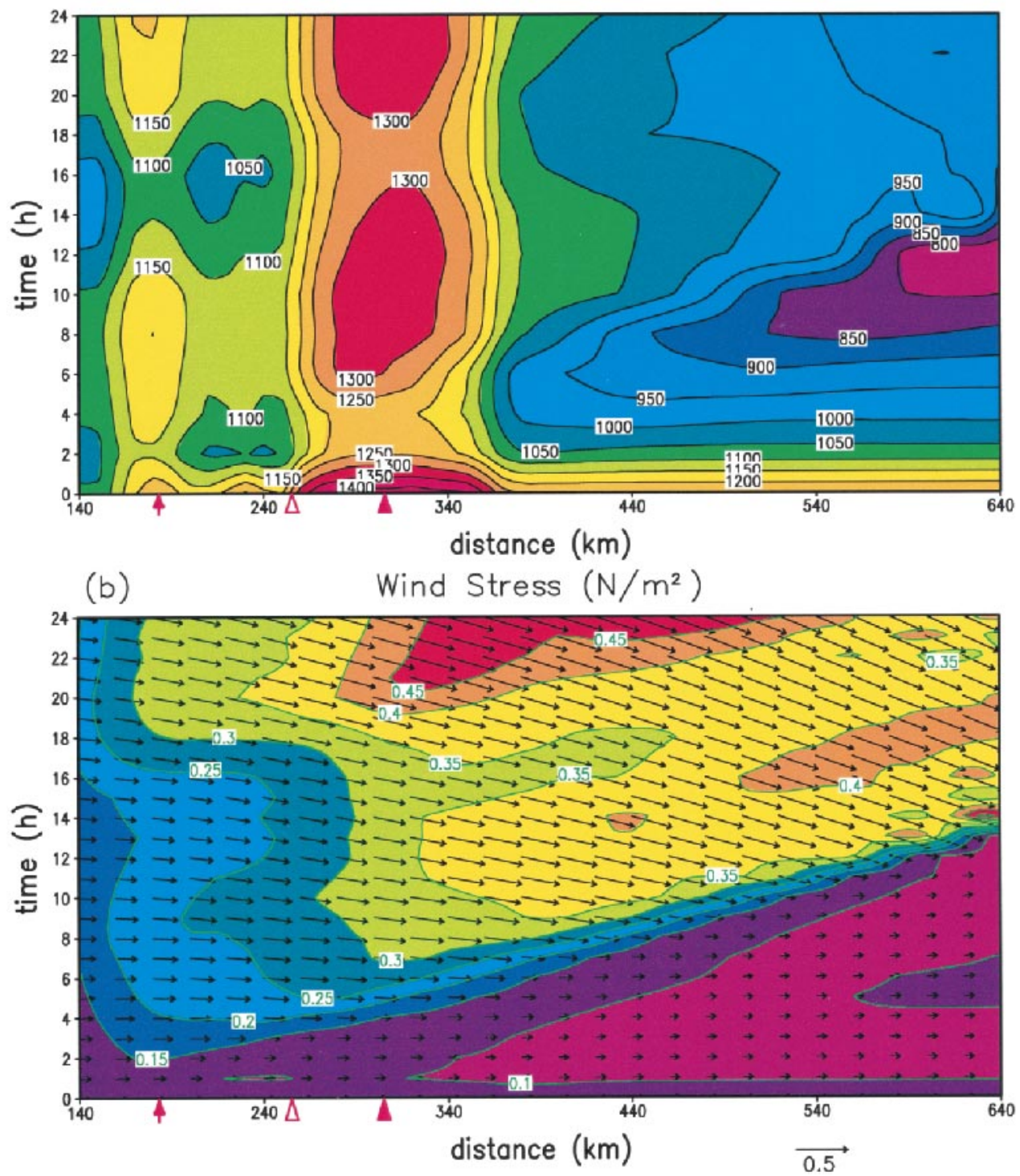

FIG. 7. Temporal and spatial distribution of the (a) total heat flux and (b) wind stress in the fully coupled experiment. Contour interval is $50 \mathrm{~W} \mathrm{~m}^{-2}$ for the heat flux, and $0.05 \mathrm{~N} \mathrm{~m}^{-2}$ for wind stress. The scale vector of $0.5 \mathrm{~N} \mathrm{~m}^{-2}$ is shown at the bottom.

temperature and humidity differences are smaller. Bane and Osgood (1989) observed an SST decrease of $1.5^{\circ} \mathrm{C}$ in the Gulf Stream in 5 days caused by the late January 1986 cold air outbreak. The same value was predicted by the forced model of H. Xue et al. (1995). According to the present study, most of this change should have occurred during the cold air outbreak phase. On the other hand, both H. Xue et al. (1995) and this study predict an increase of mixed layer depth that is too large when compared with the $35-\mathrm{m}$ change observed by Bane and Osgood (1989). It is mainly because the mixed layer depths in both models prior to the onset of the atmospheric forcing are shallower than those observed, and the temperature gradient near the base of the mixed layer prior to the onset of the atmospheric forcing is smaller than that observed. The final mixed layer distribution that increases from 50-m depth west of the Gulf Stream to about 120 -m depth east of the stream agrees reasonably well with observational results of Bane and Osgood (1989).

Figure 10 shows the change in modeled downstream velocity of the Gulf Stream in response to the cold air outbreak. The velocity anomaly results from the combined effects of wind-driven Ekman flow and the lateral displacement of the Gulf Stream that is due to advection by the wind-driven Ekman current. Since both the syn- 

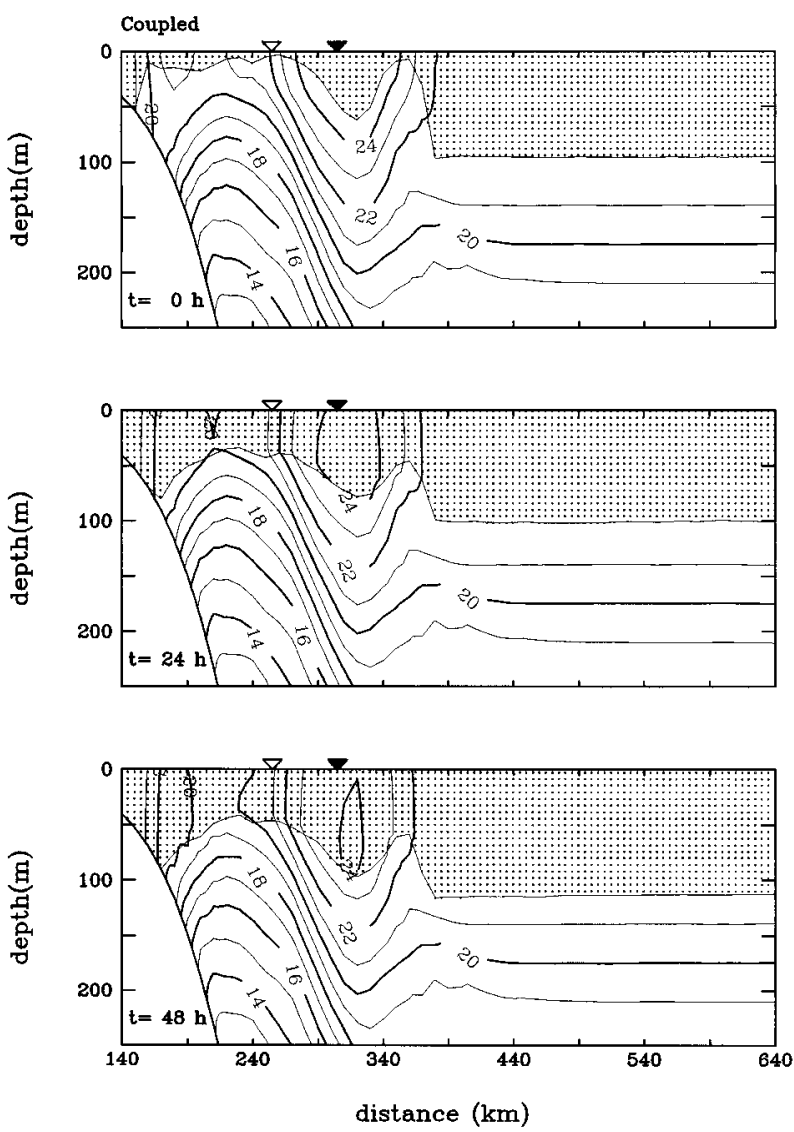

FIG. 8. Temperature distribution in the upper ocean from 0 to 250 $\mathrm{m}$ in the fully coupled experiment. Shaded areas represent the mixed layer. The upper, middle, and lower panels are at 0,24 , and $48 \mathrm{~h}$, respectively. Contour interval is $1^{\circ} \mathrm{C}$.

optic and the mesoscale winds behind the low-level atmospheric front are mainly from the west, they induce southward Ekman flow near the surface with a maximum of about $22 \mathrm{~cm} \mathrm{~s}^{-1}$. The increase in downstream velocity between 70- and 120-m depth represents the lower portion of the Ekman spiral, which deepens from 24 to $48 \mathrm{~h}$ as the OML penetrates deeper (Fig. 9b). On the other hand, the northerly wind seen in Figs. 5b, 5d, 5f, and $5 \mathrm{~h}$ generates a shoreward Ekman transport that advects the Gulf Stream onshore, which tends to increase (decrease) velocity west (east) of the Gulf Stream core. However, at the surface the southward Ekman velocity due to westerly winds dominates the velocity change due to the onshore displacement of the stream.

Similar to the forced model of H. Xue et al. (1995), a strong alongshore current appears near the coast, which is a result of the use of a two-dimensional model. This may be seen in the analytical solution of sea level setup along a straight, open coast in response to offshore wind (Csanady 1979). In that situation, a pulse propagates away from the coast, and a wake of near-inertial oscillations is left behind the pulse. Once this wake decays, a sea level setup is established, but only at dis- (a)

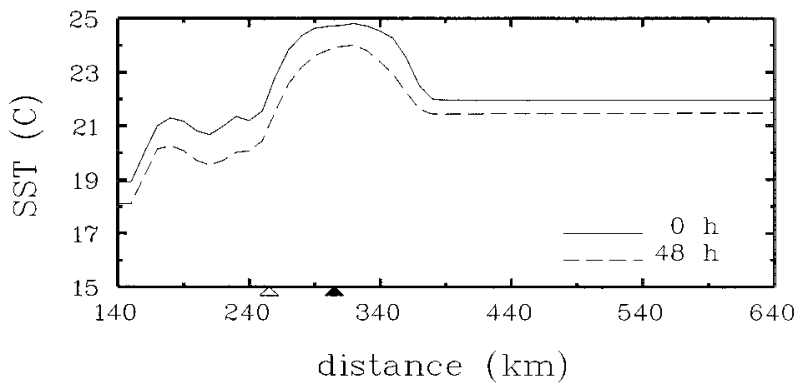

(b)

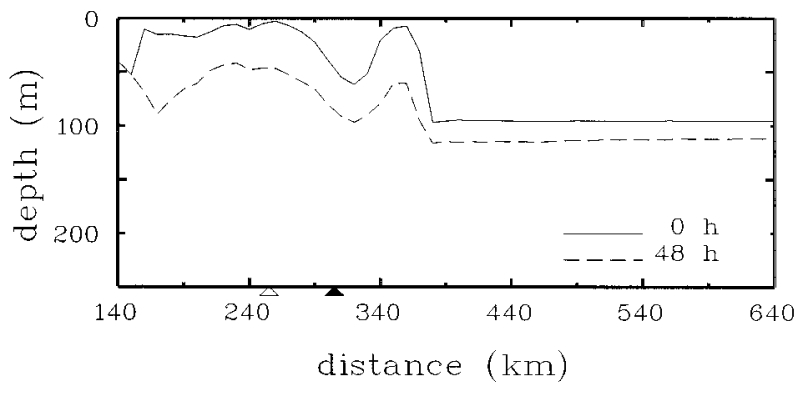

FIG. 9. Changes of the (a) SST and (b) mixed layer depth in the fully coupled experiment.

tances on the order of the Rossby radius from the coast. It is there that transient cross-shore transport appears, allowing the establishment of an alongshore transport. Farther away, the action of wind stress is balanced by the Coliolis force due to the Ekman transport parallel to the coast.
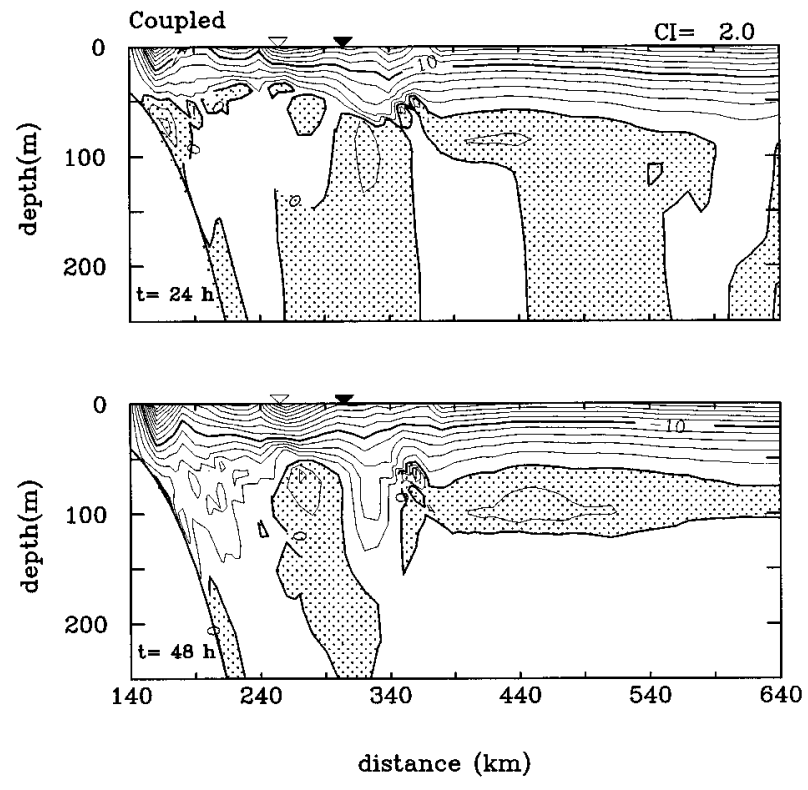

FIG. 10. Downstream velocity anomaly, which is obtained by subtracting the velocity at $0 \mathrm{~h}$ from the instantaneous velocity. Contour interval is $2 \mathrm{~cm} \mathrm{~s}^{-1}$. Shaded areas represent northward flows. 


\section{Ocean-atmosphere feedback}

To assess the feedback between the atmosphere and the ocean during a cold air outbreak, two additional experiments were performed. In the uncoupled experiment the SST is fixed. In the partially coupled experiment, only the synoptic wind and the heat flux are exported from the atmospheric model to the oceanic model. Recall that we refer to the effect of reduced SST (due to cold air flowing over the ocean surface) on the atmosphere as the feedback from the ocean to the atmosphere, and the effect of the mesoscale winds (forced by the SST field) on the ocean, as the feedback from the atmosphere to the ocean.

The structure of the lower atmosphere at $12 \mathrm{~h}$ in the uncoupled experiment is shown in Fig. 11. In comparison with the fully-coupled experiment at $12 \mathrm{~h}$ (Figs. $4 c, 4 d, 5 c, 5 d, 6 c$, and $6 d$ ), it is clear that patterns do not change significantly and their magnitudes are nearly the same. The smallness of the difference between the fully coupled experiment and the uncoupled experiment can be explained easily by the similar heat fluxes in these two experiments. Time sequences of heat flux distribution in the cross-shore direction from the fully coupled experiment and the uncoupled experiment are shown in Fig. 12. This figure is patched together using 13 panels. Each panel describes cross-shore distributions of the heat flux at specific times: $0 \mathrm{~h}, 4 \mathrm{~h}$, and so on.

The heat flux over the land is rather small in both experiments during most of the time except for around noontime (12 and $36 \mathrm{~h}$ ) when the land is relatively warm. At these times the land surface temperature (and thus the magnitude of air-land temperature difference) increases due to diurnal warming; however, the land surface temperature is still relatively cold with respect to Gulf Stream temperature. Four hours later the heat flux over the land decreases again as the land temperature decreases. The air over the land has been warmed during this period by absorbing the heat released from the land upwind. The heat flux increases dramatically from over the land to over the water. It has two peaks over the ocean, a weak one over the warm filament and a strong one over the Gulf Stream. For both experiments, the first $4 \mathrm{~h}$ again represent the initial adjustment period in which the initially cold and dry lower atmosphere is being rapidly modified by the oceanic heating. By $8 \mathrm{~h}$, the cold air has advanced over the Gulf Stream, and cold air advection and oceanic heating have nearly reached an equilibrium. By $16 \mathrm{~h}$, the cold air extends beyond the eastern boundary of the study area, and after this time the heat flux remains at a relatively steady level everywhere over the ocean. Obviously, the ocean loses less heat in the fully coupled experiment because SST decreases as a result of heat loss, thereby reducing the air-sea temperature difference and, thus, the heat flux. Additionally, there is no difference between these two experiments at the initial hour and over the land (the dashed curve in Fig. 12). The differences exist mostly over the shelf water and the Gulf Stream, and they increase with time. The maximum difference west (upwind) of the Gulf Stream core is about $6 \%$ of the heat flux itself at $12 \mathrm{~h}$, and it reaches about $8 \%$ by 24 $\mathrm{h}$ and about $10 \%$ by $48 \mathrm{~h}$. At this point, the similarities between the fully coupled and the uncoupled experiments suggest that the feedback from the ocean to the atmosphere (i.e., the effect of reduced SST on the atmosphere) is not of leading importance.

Since the heat flux does not change much from the fully coupled to the uncoupled experiment, the next step is to examine the momentum flux. In the partially coupled experiment, the mesoscale winds induced by oceanic heating are removed from the forcing of the ocean model. Figure 13 shows the upper-ocean thermal structure and its change in this experiment. The difference between the fully coupled experiment and the partially coupled experiment is small, suggesting that the upperocean temperature change during such events is primarily controlled by the heat loss from the ocean. In contrast, the oceanic downstream velocity anomaly is drastically reduced when the mesoscale winds are excluded (Fig. 14). Recall that the wind stress associated with the total wind field (synoptic plus mesoscale) is about $0.3-0.5 \mathrm{~N} \mathrm{~m}^{-2}$ (Fig. 7b), and that results in a decrease of about $20 \mathrm{~cm} \mathrm{~s}^{-1}$ in the near-surface downstream oceanic velocity across most of the domain (Fig. 10). The largest decrease of downstream velocity in the partially coupled experiment is only about $10 \mathrm{~cm} \mathrm{~s}^{-1}$ in a localized, near-surface area to the west of the Gulf Stream core where the heat flux and vertical gradient of the downstream velocity are large and cooling enhances momentum exchange in the vertical. The considerable difference in the oceanic downstream velocity between the fully coupled and the partially coupled experiments suggests that the atmospheric feedback to the ocean through the mesoscale winds on the ocean surface is important to the upper-oceanic velocity field during cold air outbreaks.

To help understand the different impacts of the feedback to the atmosphere and the ocean, we computed the amount of heat exchanged between the ocean and the atmosphere in comparison with $\Delta H_{\text {atm }}$ and $\Delta H_{\text {oce }}$. Here $\Delta H_{\text {atm }}$ is the heat content in the lower atmosphere from the surface to $2000-\mathrm{m}$ height, defined as

$$
\begin{aligned}
& \int_{0}^{2000 \mathrm{~m}} \int_{0}^{1 \mathrm{~m}} \int_{140 \mathrm{~km}}^{640 \mathrm{~km}}\left(\rho_{a} C_{p a} \theta_{a}\right)_{t=24 \mathrm{~h}} d x d y d z \\
& -\int_{0}^{2000 \mathrm{~m}} \int_{0}^{1 \mathrm{~m}} \int_{140 \mathrm{~km}}^{640 \mathrm{~km}}\left(\rho_{a} C_{p a} \theta_{a}\right)_{t=0 \mathrm{~h}} d x d y d z,
\end{aligned}
$$

and $\Delta H_{\text {oce }}$ is the heat content in the upper ocean from the surface to $100-\mathrm{m}$ depth, defined as 


$$
\begin{aligned}
\int_{0}^{100 \mathrm{~m}} & \int_{0}^{1 \mathrm{~m}} \int_{140 \mathrm{~km}}^{640 \mathrm{~km}}\left(\rho_{w} C_{w} \theta\right)_{t=24 \mathrm{~h}} d x d y d z \\
& -\int_{0}^{100 \mathrm{~m}} \int_{0}^{1 \mathrm{~m}} \int_{140 \mathrm{~km}}^{640 \mathrm{~km}}\left(\rho_{w} C_{w} \theta\right)_{t=0 \mathrm{~h}} d x d y d z .
\end{aligned}
$$

Here, $\rho_{a}$ and $\rho_{w}$ are the density of air and the density of seawater, respectively, calculated using equations of state; and $C_{p a}$ and $C_{w}$ are specific heat of air and seawater, respectively. Assuming a unit length in the alongshore direction, the amount of heat lost from the ocean to the atmosphere, $4.68 \times 10^{13} \mathrm{~J}$ in a period of 1 day, is not even $0.1 \%$ of the total heat content in the upper ocean $\left(6.82 \times 10^{16} \mathrm{~J}\right)$. The modification to the upperocean heat content is therefore small and so is the feedback of the modification to the atmosphere. On the other hand, the amount of heat received by the atmosphere is about $20 \%$ of the total heat content of the lower atmosphere $\left(2.62 \times 10^{14} \mathrm{~J}\right)$. Therefore, the modification to the lower-atmosphere heat content is substantial, and the mesoscale winds driven by this addition of heat significantly modify the upper-ocean currents.

\section{Summary}

The two-dimensional ARPS has been coupled with the two-dimensional POM to examine air-sea interactions across the Gulf Stream off the southeastern United States during a cold air outbreak. With the coupled model results, we have described the structure and evolution of the MABL and the OML, and have quantified the effects of feedback on the mesoscale and synoptic-scale motions and thermal fields in the atmosphere and ocean during such events.

Initialized with the observed 28 January 1986 cold air outbreak conditions, the model shows that a shallow mesoscale atmospheric front develops over the Gulf Stream and progresses eastward with the prevailing airflow due to both the oceanic heating and the upwind cold air advection. Potential temperature in the lower atmosphere increases in the seaward direction by about $12 \mathrm{~K}$ with the largest gradient west of the Gulf Stream core. Correspondingly, the height of the MABL increases from $800 \mathrm{~m}$ over the shelf to $2000 \mathrm{~m}$ over the Gulf Stream core, then more gradually to $2500 \mathrm{~m}$ east of the stream. Atmospheric TKE is small over the shelf and increases over the Gulf Stream, and it is small near the surface and increases to a maximum around midheight of the MABL. The maximum TKE is about 5-6 $\mathrm{m}^{2} \mathrm{~s}^{-2}$. Associated with the atmospheric temperature front, a mesoscale circulation develops in the lower atmosphere. A strong updraft leads the front and moves eastward with the front, while a downdraft occurs over the shelf and later over the shoreward side of the Gulf Stream. The downdraft results in wind intensification behind the front where the westerly wind increases by as much as $6 \mathrm{~m}$ $\mathrm{s}^{-1}$ and a northerly wind of $5 \mathrm{~m} \mathrm{~s}^{-1}$ appears. The low- level winds remain strong even when the mesoscale atmospheric front has moved away from the Gulf Stream. Another effect of the downdraft is to keep the shelf region relatively cloud free. Clouds begin near the shoreward edge of the Gulf Stream, and cloud-top heights increase in the seaward direction. Precipitation occurs east of the Gulf Stream, and the location of the maximum precipitation is consistent with the location of the updraft.

In general, the modeled MABL and the mesoscale circulation agree well with the observations obtained during the Genesis of Atlantic Low Experiment (Bane and Osgood 1989; Wayland and Raman 1989; Grossman and Betts 1990), except that east of the Gulf Stream Grossman and Betts (1990) observed an offshore-upward tilt of isentropes in the lower MABL, which is not reproduced by the model. This is most likely due to the horizontally homogeneous initial condition used in the model. In the real world the gradually decreasing airsea differences in temperature and moisture content result in weaker turbulent mixing in the MABL east of the Gulf Stream, which may in turn reduce the vertical scale of subgrid-scale turbulence. Therefore, a nonhomogeneous initial condition and a model-determined turbulence length scale should be incorporated in future studies to obtain more realistic isentrope distributions.

The response of the upper ocean to cold air outbreaks in this coupled model is similar to that in the forced model of H. Xue et al. (1995). The mixed layer deepens by about $40 \mathrm{~m}$ and the surface temperature decreases by about $1{ }^{\circ} \mathrm{C}$, also comparable with the observed changes during the January 1986 cold air outbreak (Bane and Osgood 1989). Oceanic Ekman flow associated with the strong postfrontal westerly winds reduces the surface northward oceanic velocity by more than $20 \mathrm{~cm} \mathrm{~s}^{-1}$. A shoreward displacement of the Gulf Stream, clearly seen from the downstream velocity anomaly below $50 \mathrm{~m}$, is caused by the oceanic Ekman transport associated with the northerly winds. Similar to the finding of H. Xue et al. (1995), the effects of cooling on the velocity are obscured by the strong response to winds.

The maximum surface heat flux in the fully coupled experiment is just over $1300 \mathrm{~W} \mathrm{~m}^{-2}$, which is comparable to the observed estimate of $1500 \mathrm{~W} \mathrm{~m}^{-2}$ of $\mathrm{H}$. Xue et al. (1995). The modeled heat flux is somewhat high over the outer shelf because the particular realization of the ocean temperature field chosen includes a warm filament, and so the ocean surface temperature is relatively high there. Differences in the total heat flux between the fully coupled experiment and the uncoupled experiment are less than $10 \%$, suggesting that the oceanic feedback to the mesoscale atmospheric features might not be of leading importance. Lending support to this conclusion are the similarities in the lower atmosphere between these two experiments and the previous model studies using fixed SST (Warner et al. 1990; Huang and Raman 1991). On the other hand, when the mesoscale winds induced by the ocean-to-atmosphere heat flux are excluded, the downstream oceanic velocity 

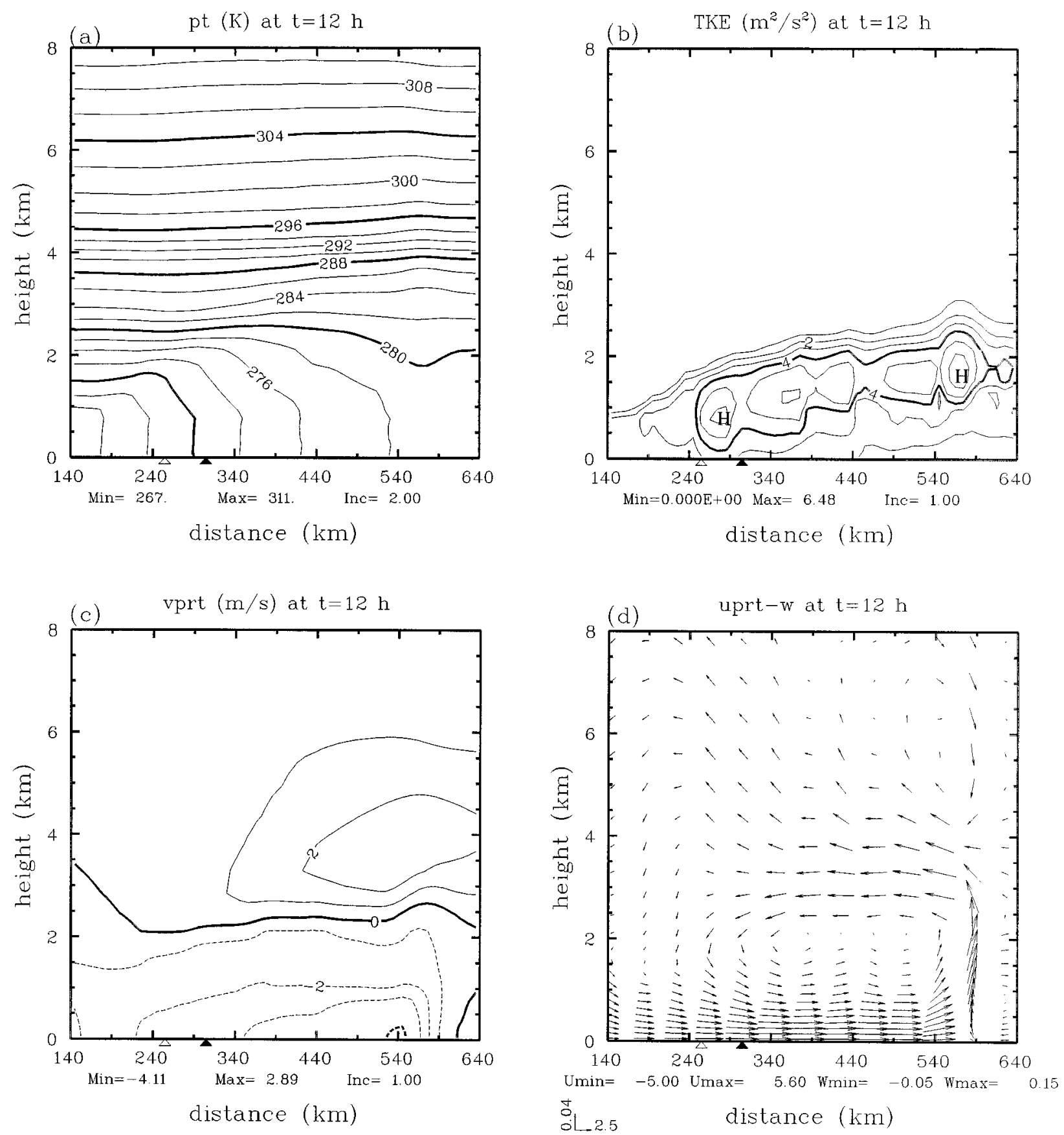

FIG. 11. Lower-atmospheric structure and mesoscale winds at $12 \mathrm{~h}$ in the uncoupled experiment: (a) potential temperature, (b) TKE, (c) $v$ anomaly, (d) $u-w$ anomaly, (e) mixing ratio of cloud water, and (f) mixing ratio of rainwater. Contour intervals are $2 \mathrm{~K}$ for potential temperature, $1 \mathrm{~m}^{2} \mathrm{~s}^{-2}$ for TKE, $1 \mathrm{~m} \mathrm{~s}^{-1}$ for $v$ anomaly, $0.1 \mathrm{~g} \mathrm{~kg}^{-1}$ for cloud water, and $0.01 \mathrm{~g} \mathrm{~kg}^{-1}$ for rainwater. Scale vectors for $u-w$ anomaly, in $\mathrm{m} \mathrm{s}^{-1}$, are shown at the lower-left corner of (d). Dashed contours in (c) represent northerly winds.

anomaly is much smaller. Southward oceanic Ekman flow in response to only the synoptic wind (westerlies of about $10 \mathrm{~m} \mathrm{~s}^{-1}$ ) is on the order of several centimeters per second, whereas it is more than $20 \mathrm{~cm} \mathrm{~s}^{-1}$ when the mesoscale winds are taken into account. The reason for this is that the wind stress increases by a factor of 3-4 when the mesoscale winds are included. The effect of cooling on the velocity distribution in the upper ocean is to reduce the shear of the downstream velocity in the Gulf Stream, and this is shown clearly in the partially coupled experiment. Since the response of the upperocean velocity field to the mesoscale winds dominates over the response to the synoptic winds, the modification to the atmosphere caused by the air-sea fluxes (i.e., the 


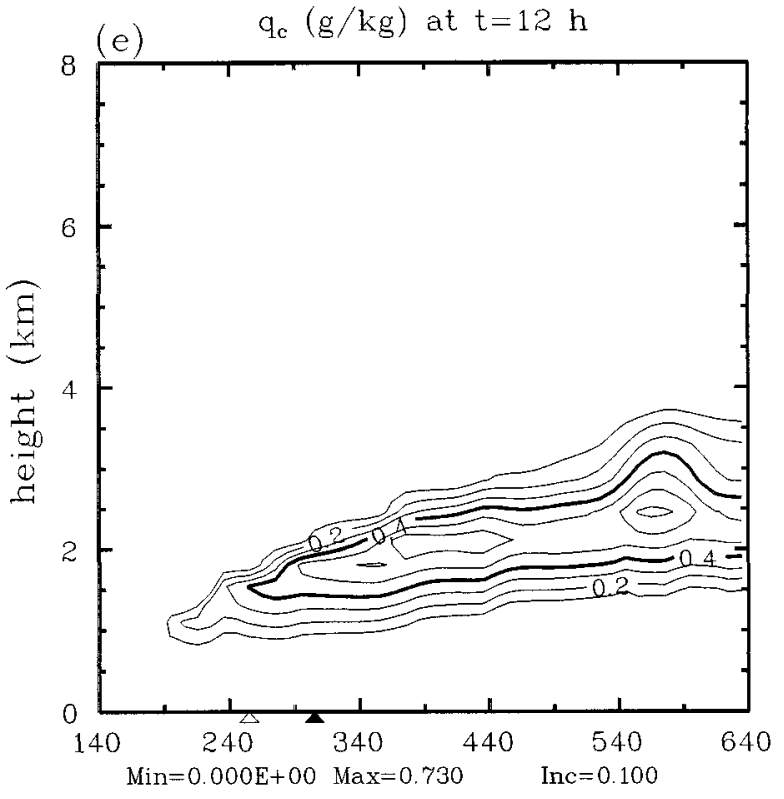

distance $(\mathrm{km})$

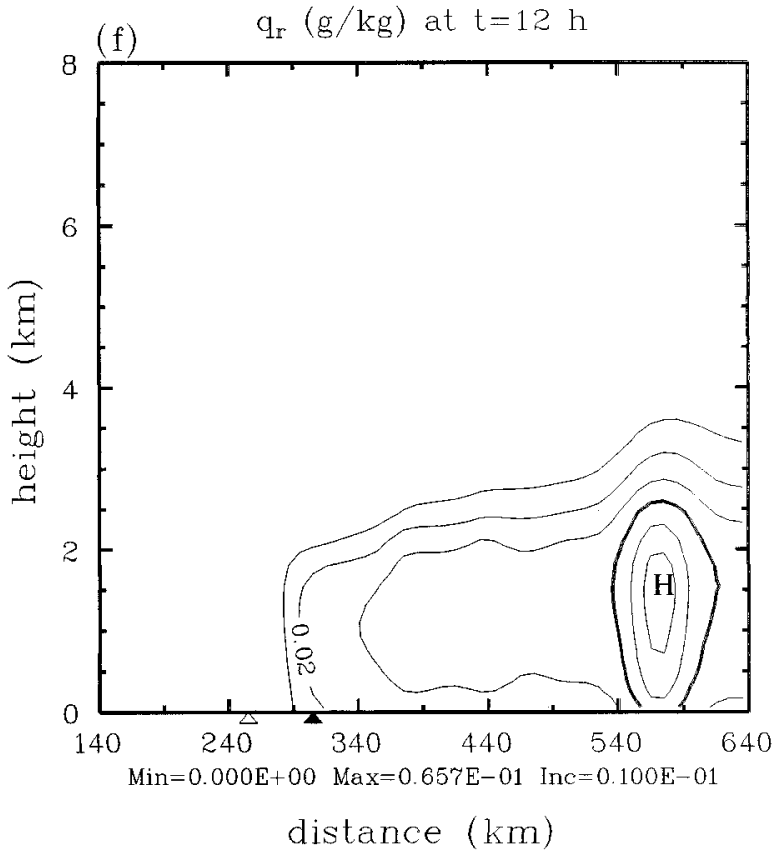

distance $(\mathrm{km})$

FIg. 11 (Continued)

mesoscale winds) does modify the ocean considerably. That is, the atmospheric feedback to the ocean is significant.

The use of a two-dimensional model has been motivated by the fact that the alongshore scale of cold air outbreaks is large, and thus heat fluxes and wind stress typically vary little in the alongshore direction. Even so, there are downstream SST gradients in the Gulf Stream and alongshore SST gradients on the shelf that can be large due to processes such as intrusions of Gulf

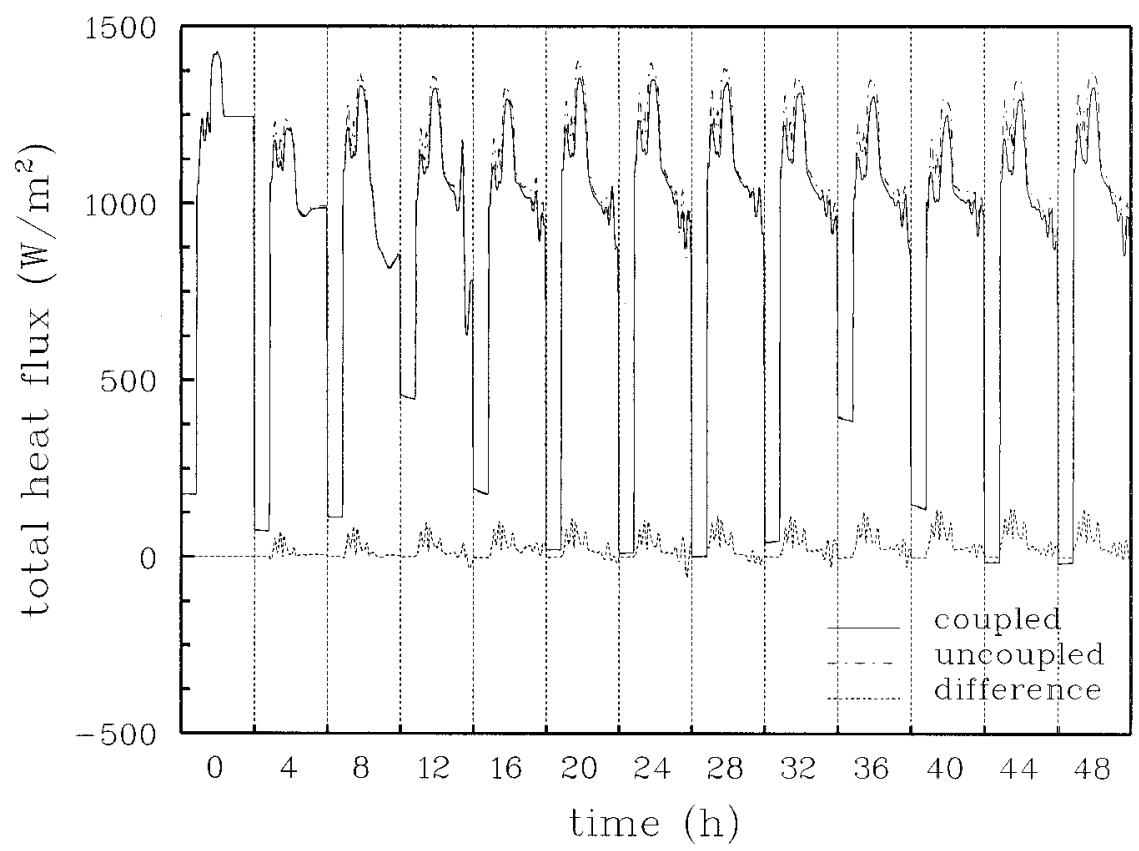

FIG. 12. Thirteen panels, separated by straight vertical lines, are snapshots of cross-shore distributions of the total surface heat flux at $0,4, \ldots, 48 \mathrm{~h}$, respectively. Solid curves are for the fully coupled experiment, dashed-dotted curves are for the uncoupled experiment, and the dashed curves are the differences between these two experiments. 

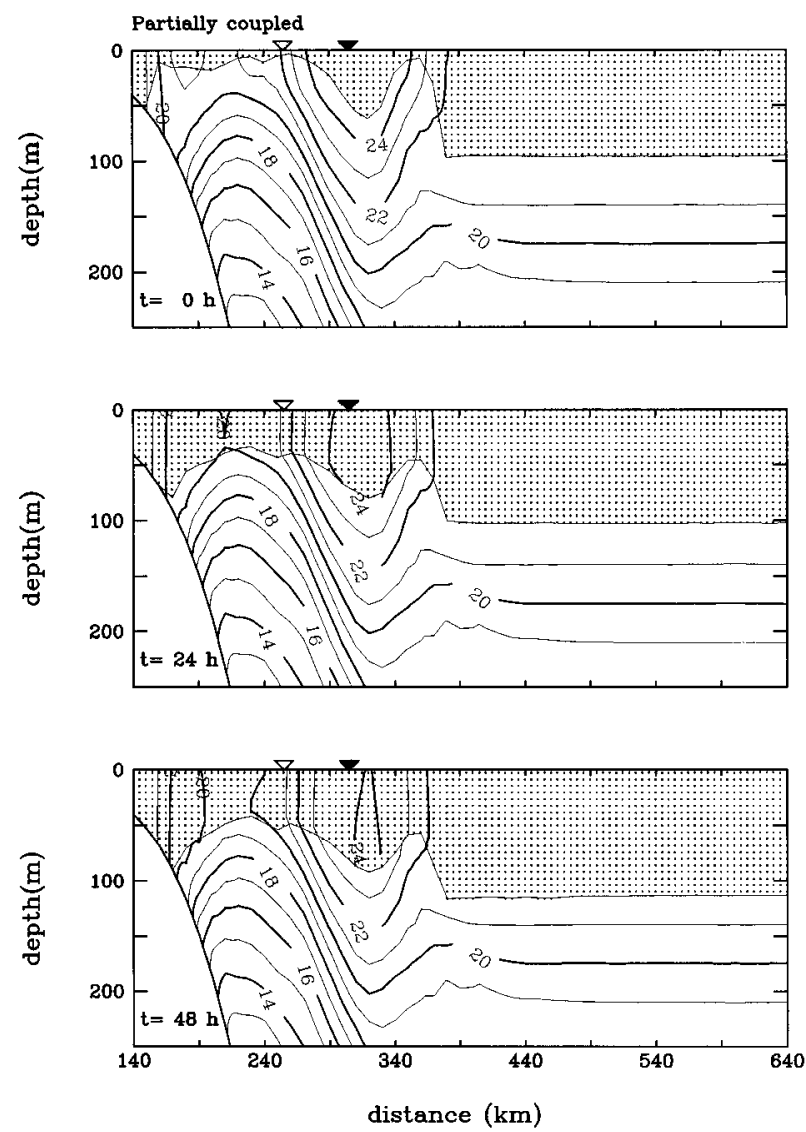

FIG. 13. Similar to Fig. 8 but for the partially coupled experiment.

Stream meanders into the shelf. Additionally, the orientation of a given atmospheric cold front, depending upon the location and the movement of the low pressure center, is not necessarily parallel to the coastline. In short, there are a number of mechanisms that can generate alongshore gradients which may modify the airsea interaction processes simulated by two-dimensional models. Furthermore, as a winter storm travels across the eastern seaboard and the Gulf Stream, synoptic conditions in the atmosphere evolve. Previous studies, like the present one, have typically focused on the cold air outbreak phase of the storm, which lasts about 1-2 days. The impact of such a storm on the ocean, however, is only partially captured by the cold air outbreak phase alone, since synoptic winds change in direction from prestorm southeasterly to poststorm westerly and northwesterly. These issues should be dealt with in due course using models with increasing complexity.

Acknowledgments. This study benefited from the efforts of many scientists associated with the GALE program and the expert flight crews of the NOAA P-3 and the NCAR Electra. Aircraft mission scientists were John Bane, Robert Grossman, and Sethu Raman. We thank Sethu Raman for providing us with the mesoscale atmospheric model of Huang and Raman (1990) to get us started on this
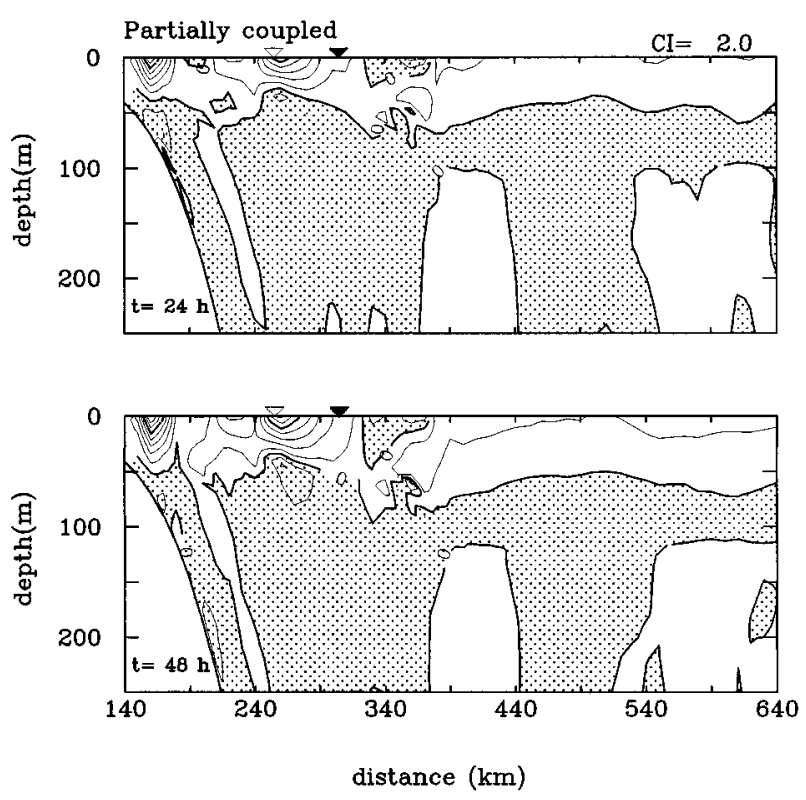

FIG. 14. Similar to Fig. 10 but for the partially coupled experiment.

project. We are especially grateful to all the people who developed the Advanced Regional Prediction System and made it available to the scientific community. We are pleased to acknowledge the computational support provided by the North Carolina Supercomputing Center. This work was supported by National Science Foundation Grants OCE-9508165 to the University of Maine and OCE-9314198 to the University of North Carolina.

\section{APPENDIX}

\section{A Sensitivity Study of Various Parameterization Options in ARPS}

With its wide selection of options, ARPS is suitable for many applications in small-scale to mesoscale weather events. A list of available parameterization is given in (M. Xue et al. (1995). We found that model results can be sensitive to a number of parameterizations. The sensitivity study discussed in this section focuses on the effects the TKE closure scheme, the PBL parameterization, and the drag coefficients have on the MABL development, since the air-sea interaction processes during cold air advection over the Gulf Stream impact most severely the lower atmosphere. A set of uncoupled experiments has been performed with fixed SST in which the model domain, the initial condition, and the SST are the same as those used by Huang (1990). Options are evaluated by comparing the results with those of Huang (1990).

\section{a. Subgrid-scale turbulence}

If subgrid-scale turbulence is anisotropic, the vertical and horizontal turbulence mixing coefficients are cal- 

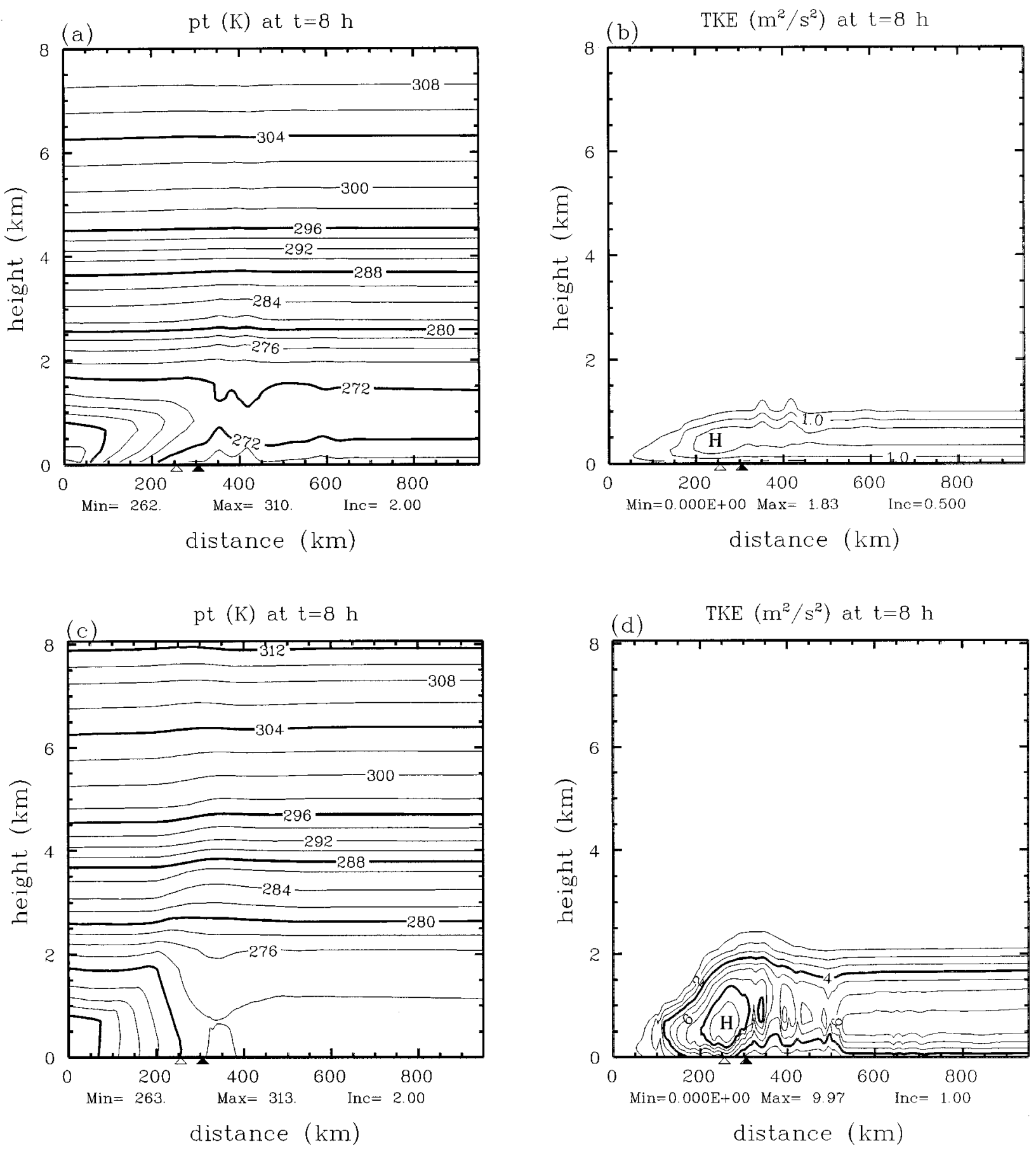

FIG. A1. Comparison of model results using different vertical turbulence scales. (a) and (b) Potential temperature and TKE in the case of anisotropic subgrid scale turbulence; (c) and (d) potential temperature and TKE in the case of isotropic subgrid-scale turbulence. Contour intervals are $2 \mathrm{~K}$ for potential temperature, and $1 \mathrm{~m}^{2} \mathrm{~s}^{-2}$ for TKE.

culated with different vertical and horizontal subgrid turbulence scales. The vertical turbulence scale, in this case, is controlled by the grid increment in the vertical. If subgrid-scale turbulence is isotropic, the model assumes the same horizontal and vertical subgrid turbulence scale, which is about one order greater than the vertical turbulence scale in the anisotropic case for our study. Figure A1 compares the potential temperature and the TKE of the experiment assuming anisotropic subgrid-scale turbulence, with their counterparts from the experiment assuming isotropic subgrid-scale turbulence. The TKE levels and the MABL height are much lower 

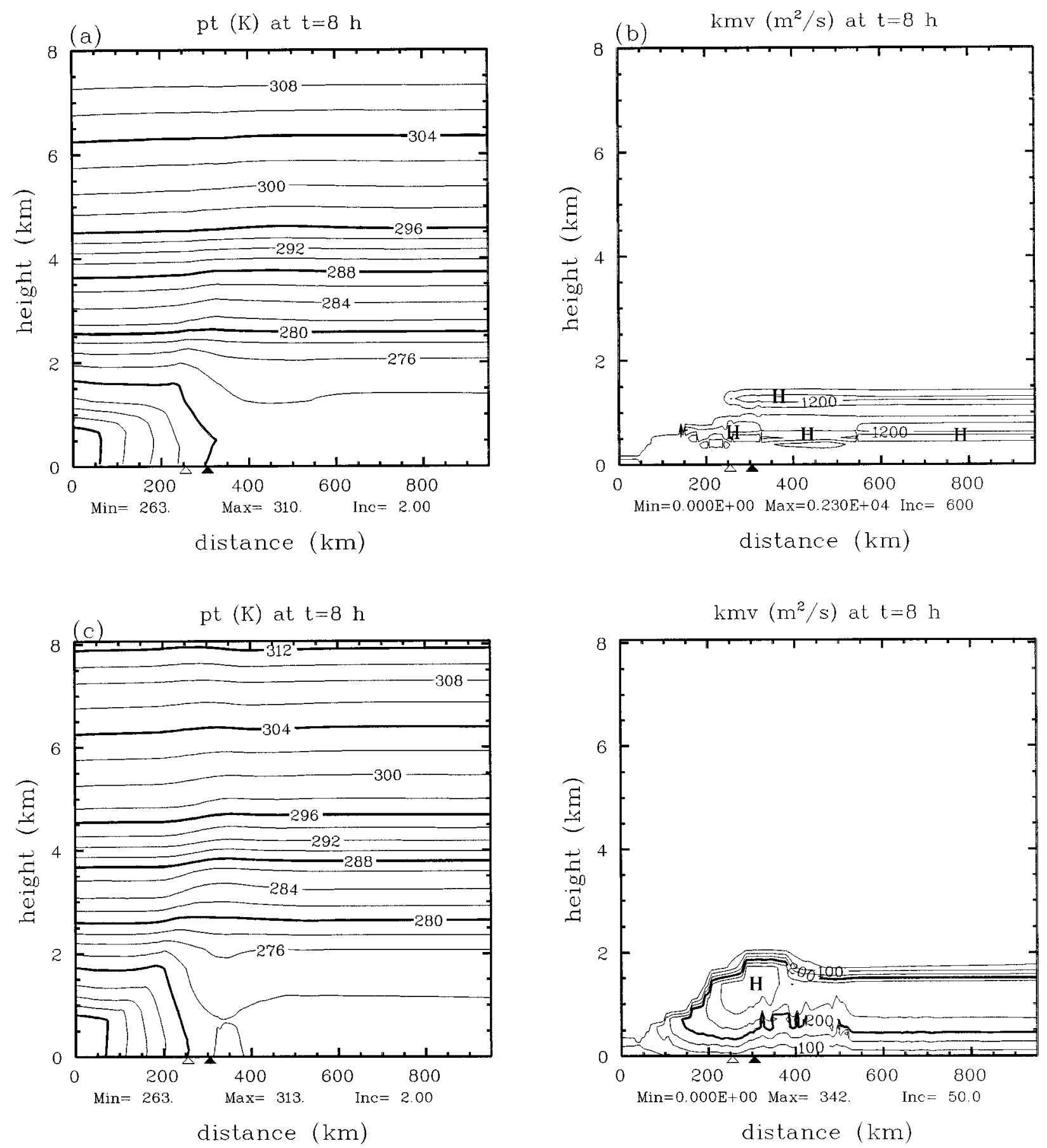

FIG. A2. Comparison of model results using different turbulence closure schemes. (a) and (b) Potential temperature and vertical eddy viscosity in the experiment using the Smagorinsky scheme; (c) and (d) potential temperature and vertical eddy viscosity in the experiment using 1.5-order turbulence closure. Contour intervals are $2 \mathrm{~K}$ for potential temperature, $600 \mathrm{~m}^{2} \mathrm{~s}^{-2}$ for eddy viscosity in (b), and $50 \mathrm{~m}^{2} \mathrm{~s}^{-2}$ for eddy viscosity in (d).

in the anisotropic case compared to those of Huang (1990), whereas they are of the same order as those of Huang (1990) in the isotropic case. The reason is probably that during cold air outbreaks, convection is very strong over the Gulf Stream, and thus the vertical tur- bulence scale is much greater than the grid increment in the vertical. On the other hand, isentropes tend to tilt offshore-upward in the lower atmosphere in the experiment assuming anisotropic subgrid-scale turbulence. The reason is that relatively weak turbulent mixing can- 
not move the heat upward efficiently, resulting in excessive warming near the surface. Thus, $\theta$ is higher at the surface and reduces slightly around midheight in the MABL.

\section{b. TKE closure scheme}

A low-level atmospheric pattern similar to that of Huang (1990) can be obtained by using the Smagorinsky (1963) first-order TKE closure scheme. However, the resultant turbulence mixing coefficient is one order too large (Figs. A2a and A2b). By using a 1.5-order TKE closure and assuming isotropic subgrid-scale turbulence, it is possible to obtain a low-level atmospheric pattern similar to using the Smagorinsky scheme, while still keeping the vertical turbulence mixing coefficient in a reasonable range (Figs. A2c and A2d).

\section{c. Drag coefficient}

ARPS allows constant or stability-dependent drag coefficients. When using the latter option, drag coefficients are functions of the modeled wind speed and surface layer stability. In this study, the model-calculated bulk aerodynamic coefficient for the momentum flux (CDM) and bulk aerodynamic coefficient for the moisture flux (CDQ) are around $1.5 \times 10^{-3}$, nearly the same as estimated by Grossman and Betts (1990) from observational data.

\section{d. Computational mixing}

Second-order computational mixing is used by ARPS. Excessive computational mixing tends to destroy mesoscale structure in the lower atmosphere. On the other hand, a minimum amount of computational mixing is needed to obtain smooth output. Values of $\mathrm{cfcm} 2 \mathrm{v}=$ $\mathrm{cfcm} 2 \mathrm{~h}=0.0005 \mathrm{~s}^{-1}$ are proper for this study.

\section{REFERENCES}

Adamec, D., and R. L. Elsberry, 1985: Numerical simulations of the response of intense ocean currents to atmospheric forcing. $J$. Phys. Oceanogr., 15, 273-287.

Atkinson, L. P., E. Oka, S. Y. Wu, T. J. Berger, J. O. Blanton, and T. N. Lee, 1989: Hydrographic variability of southeastern United States shelf and slope waters during the Genesis of Atlantic Lows Experiment: Winter 1986. J. Geophys. Res., 94, 10 699-10 713.

Bane, J. M., Jr., and K. E. Osgood, 1989: Wintertime air-sea interaction processes across the Gulf Stream. J. Geophys. Res., 94, $10755-10772$.

Blumberg, A. F., and G. L. Mellor, 1987: A Description of a threedimensional coastal ocean circulation model. Three-Dimensional Coastal Ocean Models, N. Heaps, Ed., Vol. 4, Amer. Geophys. Union, 1-16.

Bosart, L. F., 1975: New England coastal frontogenesis. Quart. J. Roy. Meteor. Soc., 101, 957-978.

- 1981: The Presidents' Day snowstorm of 18-19 February 1979: A subsynoptic-scale event. Mon. Wea. Rev., 109, 1542-1566.

Businger, J. A., J. C. Wyngaard, Y. Izumi, and E. F. Bradley, 1971:
Flux-profile relationships in the atmospheric surface layer. $J$. Atmos. Sci., 28, 181-189.

Chao, S.-Y., 1992: An air-sea interaction model for cold air outbreaks. J. Phys. Oceanogr., 22, 821-842.

Csanady, G. T., 1979: The pressure field along the western margin of the North Atlantic. J. Geophys. Res., 84, 4905-4915.

Deardroff, J. W., 1972: Parameterization of the planetary boundary layer for use in general circulation models. Mon. Wea. Rev., 100, 93-106.

Doyle, J. D., and T. T. Warner, 1990: Mesoscale coastal processes during GALE IOP2. Mon. Wea. Rev., 118, 283-308.

_, and — , 1993: A three-dimensional numerical investigation of a Carolina coastal low-level jet during GALE IOP2. Mon. Wea. Rev., 121, 1037-1047.

Grossman, R. L., and A. K. Betts, 1990: Air-sea interaction during an extreme cold air outbreak from the eastern coast of the United States. Mon. Wea. Rev., 118, 324-342.

Hobbs, P. V., 1987: The Gulf Stream rainband. Geophys. Res. Lett., 14, 1142-1145.

Huang, C. Y., 1990: A mesoscale planetary boundary layer numerical model for simulations of topographically induced circulations. Ph.D. dissertation, North Carolina State University, 253 pp. [Available from UMI, 300 N. Reeb Rd., Ann Arbor, MI 48106.]

_ , and S. Raman, 1990: Numerical simulations of cold air advection over the Appalachian Mountains and the Gulf Stream. Mon. Wea. Rev., 118, 343-362.

$\longrightarrow$, and — , 1991: Numerical simulations January 28 cold air outbreak during GALE, Part II: The mesoscale circulation and marine boundary layer. Bound.-Layer Meteor., 56, 51-81.

— of a Carolina coastal front and the Gulf Stream rainband. J. Atmos. Sci., 49, 560-584.

Lee, T. N., E. Williams, J. Wang, and R. Evans, 1989: Response of South Carolina continental shelf waters to wind and Gulf Stream forcing during winter of 1986. J. Geophys. Res., 94, 10 71510754.

Liou, C.-S., C. H. Wash, S. M. Heikkinen, and R. L. Elsberry, 1990: Numerical studies of cyclogenesis events during the second intensive observation period (IOP-2) of GALE. Mon. Wea. Rev., 118, 218-233.

Mellor, G. L., 1998: Users guide for a three-dimensional, primitive equation, numerical ocean model. Princeton University, 39 pp.

- , and T. Yamada, 1982: Development of a turbulence closure model for geophysical fluid problems. Rev. Geophys. Space Phys., 20, 851-875.

Newton, C., and E. Holopainen, Eds., 1990: Extratropical Cyclones: The Erik Palmen Memorial Volume. Amer. Meteor. Soc., 262 pp.

Noilhan, J., and S. Planton, 1989: A simple parameterization of land surface processes for meterological models. Mon. Wea. Rev., 117, 536-549.

Pleim, J. E., and A. Xiu, 1995: Development and testing of a surface flux and planetary boundary layer model for application in mesoscale models. J. Appl. Meteor., 34, 16-32.

Riordan, A. J., 1990: Examination of the mesoscale features of the GALE coastal front of 25-30 January 1986. Mon. Wea. Rev., 118, 258-282

Smagorinsky, J., 1963: General circulation experiments with the primitive equations. I. The basic experiment. Mon. Wea. Rev., 91, 99-164.

Warner, T. T., M. N. Lakhtakia, J. D. Doyle, and R. A Pearson, 1990: Marine atmospheric boundary layer circulations forced by Gulf Stream sea surface temperature gradients. Mon. Wea. Rev., 118, 309-323.

Wayland, R., and S. Raman, 1989: Mean and turbulent structure of a baroclinic marine boundary layer during the 28 January 1986 cold air outbreak (GALE 86). Bound.-Layer Meteor., 48, 227254 . 
Xue, H., and J. M. Bane Jr., 1997: A numerical investigation of the Gulf Stream and its meanders in response to cold air outbreaks. J. Phys. Oceanogr., 27, 2606-2629.

- _ - and L. M. Goodman, 1995: Modification of the Gulf Stream through strong air-sea interactions in winter: Observa- tions and numerical simulations. J. Phys. Oceanogr., 25, 533557.

Xue, M., K. K. Droegemeier, V. Wang, A. Shapiro, and K. Brewster, 1995: Advanced Regional Prediction System user's guide. University of Oklahoma, $380 \mathrm{pp}$. 